Año LI. urtea

$127-2019$

Urtarrila-ekaina

Enero-junio

5

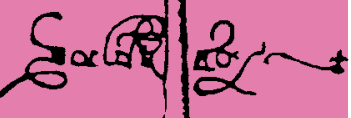

ats

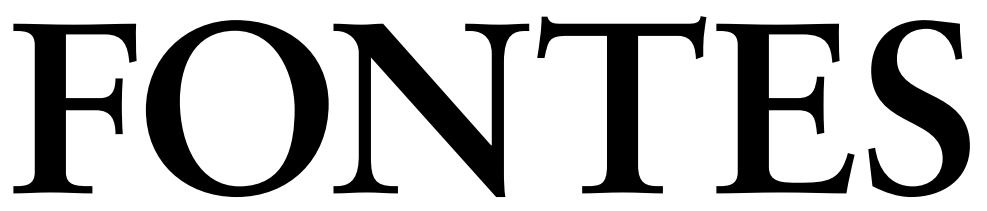

LINGVÆ

VASCONVM

STVDIA ET DOCVMENTA

SEPARATA

Azpeitiko euskararen hiztegi dialektal bat - II

Ander Beristain

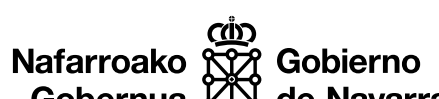

Gobernua \&S de Navarra

0000 


\section{Azpeitiko euskararen hiztegi dialektal bat - II}

Un diccionario dialectal del euskera de Azpeitia - II

A dialectal dictionary of Azpeitia Basque - II

Ander BERISTAIN

University of Illinois at Urbana-Champaign

anderb2@illinois.edu 


\section{LABURPENA}

Lan hau hiztegiaren bigarren erdia da. Aurreko lanean bezala hiztegiaren ildo nagusiak Azpeitiko euskararen azentua eta fonologia dira. Izenen eta izenondoen kasuetan, hiru forma aurkeztu dira. Lehena, flexiorik gabeko absolutiboko forma mugagabea da, eta ondorengo biak kopuladunak, bai singularrean bai pluralean. Aditzen kasuan bi forma ageri dira, partizipio perfektiboan eta ez-perfektiboan, beti 'da/du' aditz laguntzailearekin. Bestelako hitz motak forma bakarrean datoz.

Gako hitzak: euskal dialektologia; Azpeitiko euskara; hiztegia; lexikoia; soinu egituraketa.

\section{RESUMEN}

Este trabajo es la segunda mitad que compone el diccionario. Como en el escrito anterior, se centra en la acentuación y fonología del euskera de Azpeitia. En el diccionario los sustantivos y adjetivos aparecen en tres formas: la forma nuda, y seguidamente la forma de singular y plural en caso absolutivo. Los verbos aparecen en dos formas, el participio perfectivo e imperfectivo, seguido por el auxiliar de tercera persona. Las demás categorías verbales solo muestran una forma.

Palabras clave: dialectología vasca; euskera de Azpeitia; diccionario; lexicón; estructura fonológica.

\section{ABSTRACT}

This is the second half of the dialectal dictionary. Like in the previous work, the dictionary focuses on the accent and phonology of Azpeitia Basque. In the dictionary, nouns and adjectives are shown in three different forms: uninflected, absolutive singular and absolutive plural. Regarding verbs, two different forms are used throughout the dictionary: the perfective and non-perfective forms, followed by a third person singular auxiliary. As for the remaining word categories, only one form is given.

Keywords: Basque dialectology; Azpeitia Basque; dictionary; lexicon; sound structure. 
1. Hitzaurrea. 2. Metodologia. 2.1. Corpusa eraikitzen. 2.2. Parte-hartzaileak. 2.3. Nola irakurri/interpretatu hiztegia. 3. AZPEITIKO EUSKARAN GAUZATZEN DIREN ALDAKETA FONOLOGIKO NAGUSIENAK. 3.1. Bokalak. 3.2. Kontsonanteak. 3.2.1. Palatalizazioa edo bustidura. 3.2.2. Bokal arteko kontsonante galera. 3.3. Azentuazioa. 4. HIZTEGIA. 5. ERREFERENTZIAK.

\section{HITZAURREA}

Lan hau Beristainen (2018) jarraipena da. Aurreko lanean Azpeitiko euskararen deskribapen fonologiko sendoa eman zen, eta baita aldaera horretan gauzatzen diren bokal, kontsonante eta azentu aldaketa nagusienak azaldu ere. Ondoren, $A$ - $G$ hizkiak sartu ziren.

Lan honetan ez dira azalpen metodologikoak eta fonologikoak sakon plazaratu, baizik eta labur azaldu dira. Aurreko lanean azaldu ziren aldaketa fonologiko guztiak dauden arren, bakoitza laburki azaldu da. Azalpen sakon eta interdialektal bat izateko ikusi hiztegiaren lehen erdia. Azalpena eta gero, hiztegia $I$ hizkitik hasten da, eta Zrainoko hautatu diren lexiko-sarrera guztiak azaltzen dira.

Hiztegi hau egiterako orduan helburu nagusia hizkuntzalariek aurrera begira erabili ahal izango duten corpus bat eraikitzea da. Sarrera euskaraz idatzita egon arren, hiztegiko lexiko-sarrerak ingelerazko eta gaztelaniazko ordainekin datoz. Euskal dialektologiako jakintza-maila aberastea ere buruan nuen kontua da. Hiztegi dialektalen alderdian gehikuntza nabarmen bat izatea nahi dut, batik bat Gipuzkoako azpi-euskalkiei dagokien hiztegiei (Argoitia, Azkarate \& Gezuraga, 1998; Azpiazu, 2009; Del Castillo, Romo \& Giralt, 2001; Elexpuru, 2005; Etxebarria, 1965; Fraile \& Fraile, 1996; Goikoetxea, 1967; Gaminde, 2003; Izaguirre, 1970; Makazaga, 2010, besteak beste). 


\section{METODOLOGIA}

\subsection{Corpusa eraikitzen}

Hiztegi honen egitura eta definizio gehientsuenak Hualde, Elordieta eta Elordietatik (1994) eskuratu dira. Lan hori Lekeitioko euskarari buruzkoa da, eta deskribapen fonologiko bat, morfologiko bat eta lexiko bat plazaratzen ditu. Azpeitiko euskararen hiztegi dialektal honetarako, lan horren atal lexikotik abiatu gara.

Lehenengo urratsa Lekeitioko aldaeratik Azpeitiko aldaerara 'itzultzea' izan da, hori hiztegi honen egileak egin zuen. Ondoren, hiztegian parte hartu zuten partehartzaileei hainbat ariketa mota aurkeztu zitzaizkien: batean, gaztelaniazko formak emanda Azpeitiko euskarara itzultzeko eskatu zitzaien, azentua markatuz. Esaterako, «un perro, (es) el perro, (son) los perros» formak hiztunak «txakúr bat, txakurré (da), txakúrrek (die)» formetara itzuli zituzten. Nabarmentzekoa da hiztegian zehar, lexiko-sarreretan ez dela zenbatzailerik agertzen flexiorik gabeko forman eta ezta kopularik ere beste bi formetan. Bestelako ariketa motan, hiztunek hiru formak Azpeitiko aldaeran jaso zituzten, eta haiek egin behar zutena zen forma horien baiezkotasuna bermatzea edo ezeztatzea. Hiztunek bestelako modu bat bazuten hitzak esateko, azpiohar gisa dator.

\subsection{Parte-hartzaileak}

Proiektu honetan 20 gazte azpeitiarrek hartu dute parte, adin tartea = 18-24 izan da, eta bataz besteko adina $=23.3$ izan da. Hogei hiztunetatik 10 emakumezkoak dira eta gainontzeko 10ak gizonezkoak. Partaide guztiek Azpeitian D ereduko ikastetxe batean jaso zuten beren hezkuntza.

Behin corpus osoa eraikita, hiztun horietatik emakumezko batek hiztegi osoa errebisatu zuen eta zuzenketak egin zituen. Aurreko belaunaldian aldaketarik baden edo ez jakiteko, 58 urteko gizonezko Azpeitiar batek ere hiztegi osoa errebisatu zuen. Ezberdintasun horiek azpi-ohar gisa adierazi dira hiztegian.

\subsection{Nola irakurri/interpretatu hiztegia}

Hiztegian lexiko sarrerak alfabetikoki daude atonduta. Lexiko sarrerei dagokienez, hainbat kategoriatako hitzak topatuko ditugu. Hona hemen erabilitako legenda (Elhuyar Hiztegia, 2014):

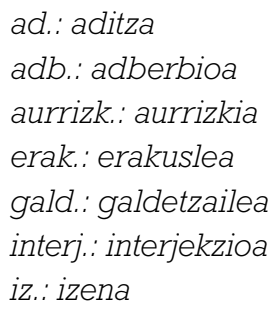

\author{
izond.: izenondoa \\ izord.: izenordaina \\ junt.: juntagailua \\ onomat: : onomatopeia \\ pred. adj.: predikatu adjektiboa \\ zenb.: zenbakia \\ zenbtz.: zenbatzailea
}


Hitz motaren arabera sarrera bakoitzak forma kopuru gehiago edo gutxiago ditu. Beristainen $(2018,12$. orr.) sailkapen bera egin da:

Izenak, izenondoak eta aditzak ez diren hitz motetan forma bakarra jaso da. Izenen eta izenondoen kasuan, berriz, hiru forma aurkeztuko dira. Lehena flexiorik gabeko forma izango da; absolutiboan doan forma mugagabea, alegia. Hurrengo bi formak kopula eta artikulu singularra eta plurala dutenak dira. Azkenik, hitzen azentua edo bokal tonikoa markatzen da azentu markaren (') bidez.

Aditzen kasuan, bi forma aurkeztuko dira: forma burutua eta ez-burutua, beti hirugarren pertsona singularrari dagozkionak, alde batetik iragankorra edo iragangaitza den jakiteko, eta bestetik, azentu aldaketarik jasatzen duen jakiteko.

\section{AZPEITIKO EUSKARAN GAUZATZEN DIREN ALDAKETA FONOLOGIKO NAGUSIENAK}

\subsection{Bokalak}

1) $\mathbf{a} \rightarrow$ e/_a

Arau fonologikoen sekuentziazioan dugun lehenengo araua beheko bokalaren igoera da, arau hau ez da Azpeitiko euskaran bakarrik gauzatzen, baizik eta gertuko beste aldaeretan ere badugu, Azkoitikoan (Del Castillo et al., 2001) eta Elgoibarrekoan (Makazaga, 2010) esaterako.

\section{2) $\varnothing \rightarrow[j] / i_{-} V$}

Hitz amaieran, - $a$ determinatzailea dugun kontestuetan gauzatzen da [j] kontsonantearen epentesia Azpeitiko euskaran. Inguruko herrietan, Azpeititik iparrera dauden horietan (Zestoan, Zumaian, eta Zarautzen, esaterako) kontsonante berdinaren epentesia dugu (Azpeitia, 2003), mendebalderantz jo ezkero, berriz, sabaiaurreko frikari ahoskabearen, [S], epentesia gauzatzen da. Honen adibide dira, esaterako, Azkoitiko eta Elgoibarko hizkerak (Del Castillo et al., 2001; Makazaga, 2010).

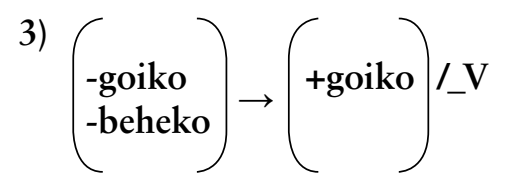

$\mathrm{e} \rightarrow \mathrm{i} / \mathrm{V}$

$\mathrm{o} \rightarrow \mathrm{u} / \mathrm{V}$

Azpeitiko euskaran erdiko bokalak goikoak bihurtzen dira bokal aurreko kontestuan. Atzetik datorren bokal hori - a determinatzailea izan behar du bokal aldaketa jazotzeko [ikusi Beristain (2018), De Rijk-en (1970, 154. orr.) Rea araua, edo Hualde \& Gaminde (1997)]. 
4) $\mathrm{a} \rightarrow \mathrm{e} /\{\mathrm{u}, \mathrm{i}\}(\mathrm{C})_{-}$

Azken arau bokalikoa asimilazio araua da, non beheko bokala erdikoa bihurtzen den aurretik goiko bokal bat dagoelako (edo kontsonante bat ere, baldin badago). Ikusi De Rijk-en (1970) Rui araua, Gaminde (2002), Zuazo (2008, 239. orr.), edo Zuloaga (2017) azalpen sakon baterako.

\subsection{Kontsonanteak}

Aldaketa kontsonantikoei dagokienez, palatalizazioa eta bokal arteko kontsonanteen galera dira nabarmendu beharrekoak:

\subsubsection{Palatalizazioa edo bustidura}

[+hobikaria] $\rightarrow$ [+sabaikaria]/i_V

Azpeitiko euskaran gauzatzen diren bustidura prozesuak asimilazio bustidurak dira $(t \rightarrow$ [c]-ren kasua izan ezik, hau afekzio bustidura baita) (Oñederra, 2004). Hitz-barnean beti gauzatzen dira baina hitz amaieran hautazkoak dira asimilazio bustidurak (Beristain, 2018).
a) $1 \rightarrow K /$ i_V
b) $\mathrm{n} \rightarrow \mathrm{n} / \mathrm{i} \_\#$; $\mathrm{n} \rightarrow \mathrm{n} / \mathrm{i} \mathrm{V}$
c) $s \rightarrow \int / i \_k$
d) $\mathrm{t} \rightarrow[\mathrm{c}](<\mathrm{tt}>) / \mathrm{i}$ _V[-goiko, -beheko]

\subsubsection{Bokal arteko kontsonante galera}

Beste hainbat euskal aldaeretan bezala Azpeitiko euskaran ere bokal arteko kontsonante galera gauzatzen da (Hualde, 1991). Horren agerpena ez da orokorra, aldakortasuna baitago hiztunetik hiztunera (Hualde \& Beristain, 2019). Halere, hurrengo testuinguruek galera baimentzen dute:

a) $\mathrm{r} \rightarrow \varnothing / \mathrm{V}[$-goikoa]_V[+goikoa edo +behekoa]

b) $d \rightarrow \varnothing /$ V_[+goikoa edo +behekoa]

c) $\mathrm{d} \rightarrow \mathrm{r}$

Hualde eta Beristainek (2019) topatu zuten $<$ d $>$ eta $<$ r $>$ kontsonanteen ahoskerari dagokionez, hitzaren morfologiak eta lexikoak berak ere eragina dutela bokal ahultzean, galeran, edo indartzean. Kontsonantea hitzaren erroan balego bokal aldaketa gauzatzen zailagoa litzateke. Flexioan badago, ordea, errazagoa izango da.

\subsection{Azentuazioa}

Hiztegian ikusi ahal den bezala, Azpeitiko euskarak azentu bereizgarria du, hau da, azentuaren kokagunea aldatuz esanahiak bereiz daitezke, esaterako, básue da (edalontzia da) baina basué da (basoa da) esaten da Azpeitian (Altuna, 1985, 334. orr.).

Hualde \& Beristainek (2017, 70. orr.) azaltzen duten bezala, «araurik orokorrenaren arabera -hitz gehienei singularrean eta mugagabean aplikatzen zaiena- azentua hiru- 
garren silaban kokatzen da, silaba hori hitz prosodikoaren azkena ez bada». Pluralen kasuan hitz gehienekin azentuak atzerantz egiten du, eta bigarren silaban kokatzen da. Hitz batzuetan, ordea, singularrak eta pluralak azentua kokagune berdinean dute (ikusi giltzurrún, giltzurrúne, giltzurrúnek), baina beste kasu batzuetan azentuaren kokagunea aldatzen da, esaterako iturrí, iturriye, itúrriyek edo alkaté, alkatie, alkátiek (Beristain, 2018).

Gaztelaniako kalkoak diren hitzetan aldakortasuna topatzen dugu. Izan ere, zenbait hiztunek bi azentudun formak onartzen zituzten, bata gaztelaniako azentua mantenduz, esaterako, famósue, eta bestea Azpeitiko euskararen azentuera erregela nagusia erregulatuz, famosúe. Proiektuko parte-hartzaileen iritzia jasotzerako orduan, denek bigarren forma nahiago zuten, lehenengoari gaztelaniaranzko kutsua egotzirik. Hitz mota horietan ikerketa gehiago egin beharra dago oraindik.

\section{HIZTEGIA}

I

iaió, iaiué, iaiúek edo yayó, yayué, yayúek (izond.): skilled / hábil, diestro.

íbai, íbaye, íbayek (iz.): river / río.

ibilli daldu, ibíltzealibiltzeu (ad.): 1. to walk; 2. to use / 1. andar; 2. usar.

ibílkera, ibílkerie, ibílkerak edo ibíllera, ibíllerie, ibíllerak (iz.): way of walking / forma

de andar.

idatzi du, idázteu (ad.): to write / escribir.

idázkera, idázkerie, idázkerak (iz.): writing / escritura (estilo).

idazlé, idazlie, idázliek (iz.): writer / escritor.

idéa, idéie, idéak (iz.): idea / idea.

idí, idiyé, idíyek ${ }^{1}$ (iz.): ox / buey.

idipróba, idipróba, idipróbak (iz.): oxen competition / concurso de bueyes.

ieltzéro, ieltzérue, ieltzéruek (iz.): mason, brick layer / albañil.

iesí in $d u$, iesí itéu (ad.): to flee / huir.

igánde, igándie, igándiek edo jái, jayé, jáyek (iz.): Sunday / domingo.

igerí (e) in du, igerí éiteu (ad.): to swim / nadar.

igerri du, igértzeu (ad.): to notice / notar.

ikástola, ikástolie, ikástolak (iz.): Basque school / escuela vasca.

ikátz, ikatzá, ikátzak (iz.): coal / carbón.

ikaxi edo ikixi du, ikáxteulikixteu (ad.): to learn / aprender.

ikerá, ikerie, ikérak (iz.): scare / miedo, susto, temor.

ikúllu, ikúllue, ikúlluek (iz.): stable / cuadra.

ikurrín, ikurríne, ikurrínek (iz.): Basque flag / bandera vasca, ikurriña.

$1 \mathrm{~d}>\mathrm{r}$ alternantzia gertatu daiteke hitz honetan eta hurrengoan, hots, irí, iriyé, iríyek eta iripróba, iripróba, iripróbak (Hualde \& Beristain, 2019). 
ikusi du, ikústeu (ad.): to see / ver.

ikutú du, ikútzeu (ad.): to touch / tocar.

ildako, ildakue, ildakuek (izond.): dead / muerto.

ill (e) in da, iltzea (ad.): to die / morir.

illábete, illábetie, illábetiek edo illébete, illébetie, illébetiek (iz.): month / mes.

illargí beté, illargí betié, illargí betiek (iz.): full moon / luna llena.

illargí, illargíye, illargíyek (iz.): moon / luna.

illé, illié, illié (iz.): hair / pelo.

illekó, illekúe, illékuek (iz.): menstruation / menstruación.

illér, illerrá, illérrak (iz.): pea / guisante.

illerá, illeríe, illérak (iz.): row / hilera.

illetá, illetie, illétak (iz.): funeral / funeral.

illobá, illobá, illóbak (iz.): nephew, niece / sobrino, -a.

illún, illuné, illúnek (izond.): dark / oscuro.

illuntásun, illuntásune, illuntásunek (iz.): darkness / oscuridad.

illúntze, illúntzie, illúntziek (iz.): sunset / anochecer.

inbiri, inbiriye, inbiriyek (iz.): envy / envidia.

indár, indarrá, indárrak ${ }^{2}$ (iz.): strength / fuerza.

indartú $d u$, indártzeu (ad.): to strengthen / reforzar, fortalecer.

indartzú, indartzúe, indartzúek (izond.): strong / fuerte.

indizíyo, indizíyue, indizíyuek (iz.): injection / inyección.

infektáu da, infektátzea (ad.): to become infected (a wound) / infectarse (una herida).

infekzíyo, infekzíyue, infekzíyuek (iz.): infection / infección.

ingúrau du, ingúratzeu (ad.): to surround / rodear.

ingúru, ingúrue, ingúruek (iz.): surroundings / alrededores.

inkiéto, inkiétue, inkiétuek (izond.): restless / inquieto.

inpernú, inpernúe, inpérnuek (iz.): hell / infierno.

inportánte, inportántie, inportántiek (izond.): important, famous / importante, de ca-

tegoría, de renombre.

inportántzi, inportántziye, inportántziyek (iz.): importance / importancia, interés.

inpórta diyo, inpórtatze zako (ad.): to matter / importar a uno.

inpresiyo, inpresiyue, inpresiyuek (iz.): impression / impresión, efecto.

insintiu $d u$, insistitzeu (ad.): to insist / insistir.

interés, interésa, interésak (iz.): interest / interés.

interésante, interésantie, interésantiek (izond.): interesting / interesante.

intxaur, intxaurre, intxaurrek (iz.): walnut / nuez.

iñoá (adb.): (to) somewhere; (to) anywhere / a algún sitio; a ningún sitio.

iñoaéz (adb.): (to) nowhere / a ningún sitio.

iñóiz (adb.): sometime, ever; never / alguna vez; nunca.

iñóize (adb., inoiz ere ez): never / nunca.

iñórrez (izord.): no one / nadie.

2 indér, inderrá, indérrak formak ere ager daitezke. 
iñúnez (adb.): nowhere / en ningún sitio.

iñuzénte, iñuzéntie, iñuzéntiek (izond.): silly / tontorrón, inocente.

ipár, iparrá, ipárrak (iz.): North / norte.

iparráize, iparráizie, iparráiziek (iz.): North wind / viento del norte.

ipiñi $d u$, ipintzeu (ad.): to put / poner, colocar.

ipúiñ, ipuiñé, ipúiñek (iz.): tale, story / cuento, relato.

ipurdi, ipurdiye, ipúrdiyek (iz.): buttocks / trasero, culo.

irabázi du, irabázteu (ad.): 1. to win; 2. to earn / ganar, vencer.

irabázle, irabázlie, irabázliek (iz.): winner / vencedor.

irakĩ $d u$, irakiteu (ad.): to boil / hervir.

irí, iriyé, iríyek (iz.): city / ciudad.

iritziye emán $d u$, iritzíye ematéu (ad.): to think, to seem to S.O. / opinar, parecer.

irríntzi, irrintzíye, irríntziyek (iz.): shout, yell / grito sonoro y prolongado que antiguamente lanzaban los pastores en los bancos de las montañas.

irríxtau da, irrixtátzea (ad.): to slip without falling / resbalar sin llegar a caerse.

irú (zenb.): three / tres.

irugiyer, irugíyerra, irugíyerrak (iz.): bacon / tocino.

itzál, itzalá, itzálak (iz.): shade / sombra.

isla, islie, islak (iz.): island / isla.

istitútu, istitútue, istitútuek (iz.): institute / instituto.

itó da, itótzea (ad.): to drown / ahogar(se).

iturrí, iturríye, itúrriyek (iz.): fountain / fuente.

itxasó, itxasúe, itxásuek ${ }^{3}$ (iz.): sea / mar.

itxi dulda, ixteulíxtea (ad.): to close / cerrar.

itxú, itxué, itxúek (iz.): blind / ciego.

itxulápiko, itxulápikue, itxulapíkuek (iz.): 1. moneybox; 2. (slang) butt crack / 1. hucha; 2. (slang) raja del culo.

itxurá, itxúrie, itxúrak ${ }^{4}$ (iz.): aspect / traza, hechura.

itxutú da, itxútzea (ad.): to become blind / volverse ciego, cegarse.

itz éin du, itzéiteu (ad.): to talk / hablar.

itz, itzé, itzek (iz.): word / palabra.

itzaldú daldu, itzáltzealitzáltzeu (ad.): to extinguish; to turn off / apagar.

iwál edo iwél (adb.): 1. perhaps; 2. alike / 1. quizá; 2. igual.

ixildú da, ixíltzea (ad.): to be quiet, to shut up / callarse.

ixillik (adb.): silently / en silencio, callando.

ixíll, ixillé, ixíllek (izond.): silent, quiet / silencioso, callado.

ixkiña, ixkiñie, ixkiñak (iz.): corner / esquina.

ixkutáu dulda, ixkutátzeulixkutátzea (ad.): to hide / esconder(se).

ixpillu, ixpillue, ixpilluek (iz.): mirror / espejo.

ixtú, ixtué, ixtúek (izond.): tight (clothes) / ajustado (se dice de la ropa).

3 Aurreko belaunaldietan itxesúe, itxésuek formak ere erabiltzen dira.

4 itxuré, itxúrie, itxúrek formak ere erabiltzen dira. 
izáera, izáerie, izáerak (iz.): way of being / forma de ser.

izár, izarrá, izárrak ${ }^{5}$ (iz.): star / estrella.

izebá, izébak edo tía, tíak (iz.): aunt / tía.

izén, izená, izénak (iz.): name / nombre.

izén du, izéteu edo izán du, izáteu (ad.): to be / ser, estar. 'Han izen naiz.' / I've been

there. / He estado alli.'

izerá, izérie, izérak (iz.): bed sheet / sábana.

izerdí, izerdiye, izérdiyek (iz.): sweat / sudor.

izerditu da, izerditzea (ad.): to sweat / sudar.

izorráu du, izorrátzeu (ad.): to ruin / echar a perder, estropear.

izótz, izotzá, izótzak (iz.): ice / hielo, helada.

izoztú dulda, izózteulizóztea (ad.): to freeze / helar(se).

iztegí, iztegíye, iztégiyek (iz.): dictionary / diccionario.

iztér, izterrá, iztérrak (iz.): thigh / muslo.

iztún, iztuné, iztúnek (izond.): talkative / hablador.

\section{J}

jabé, jabié, jabiek (iz.): owner / dueño.

jabói, jaboyé, jabóyek (iz.): soap / jabón.

jái, jayé, jáyek (iz.): holiday / fiesta.

jaiegún, jaiegúne, jaiegúnek (iz.): holiday / día festivo.

jainkó, jainkué, jainkúek (iz.): God / Dios.

jaiobérri, jaiobérriye, jaiobérriyek (iz.): newborn child / recién nacido.

jaiótz, jaiotzá, jaiótzak (iz.): birth / nacimiento.

jakin du, jakiteu (ad.): to know / saber.

jakitún, jakitúne, jakitúnek (izond.): wise, knowledgeable / sabio.

jan du, játeu (ad.): to eat / comer.

jankái, jankayé, jankáyek (iz.): banquet / banquete, comilona.

jantzi dulda, jázteuljáztea (ad.): to get dressed, to dress / vestir(se).

jarábe, jarábie, jarábiek (iz.): sirup / jarabe.

jardín, jardiñé, jardiñek (iz.): garden / jardín.

játeko, játekue, játekuek (iz.): food / comida.

jatór, jatorrá, jatórrak (izond.): nice / agradable, majo.

jatorrí, jatorríye, jatórriyek (iz.): origin / origen, ascendencia.

jatún, jatuné, jatúnek (izond.): good eater / de buen apetito.

jáun, jauné, jáunek (iz.): sir / señor.

jayó da, jayótzea (ad.): to be born / nacer.

jendé, jendié, jendiek (iz.): people / gente.

jénero, jénerue, jéneruek (iz.): merchandise / género, mercancía.

jéniyo, jéniyue, jéniyuek (iz.): temper / genio. 
jertzé, jertzié, jertziek (iz.): jersey, sweater / jersey.

jésto, jéstue, jéstuek (iz.): grimace / mueca, gesto.

jo du, jótzeu (ad.): 1. to hit; 2. to play an instrument; 3. to strike the hour / 1. pegar; 2.

tocar un instrument; 3. dar las horas.

jokalái, jokaláye, jokálayek (iz.): player; gambler / jugador.

jokáu du, jokátzeu (ad.): to play / jugar.

jokó, jokué, jokúek (iz.): game / juego.

jolastú du, jolásteu (ad.): to play / jugar.

josi $d u$, jósteu (ad.): to sew / coser.

jóstorratz, jóstorratza, jóstorratzak (iz.): sewing needle / aguja de coser.

jostún, jostuné, jostúnek (iz.): seamstress / costurera.

jóta, jótie, jótak (iz.): 1. jota, a dance; 2. the letter «J» / 1. jota (baile folclórico); 2. la

letra «J».

jubiláu da, jubilátzea (ad.): to retire / jubilarse.

jubiláu, jubiláue, jubilauek (izond.): retired / jubilado.

jubiláziyo, jubiláziyue, jubiláziyuek (iz.): retirement / jubilación.

juérga, juérgie, juérgak (iz.): party / farra, juerga.

juergista, juergístie, juergístak (iz.): merrymaker / juerguista.

jún da, jútea (ad.): to go, to leave / ir(se).

juntáu da, juntátzea (ad.): to get together; to gather / juntar(se).

justizi, justíziye, justíziyek (iz.): justice / justicia.

juxtú (adb.): tightly / ajustadamente.

juxtú-juxtú (adb.): almost; just enough / casi casi, por poco.

juzgáu du, juzgátzeu (ad.): to judge / juzgar.

juzgáu, juzgané, juzgánek (iz.): Court House / juzgado.

K

kabiú da, kabitzea (ad.): to fit / caber.

kaderá, kadérie, kadérak (iz.): hip / cadera.

kafé, kafié, kafíek (iz.): coffee / café.

kafésne, kafésnie, kafésniek (iz.): coffee with milk / café con leche.

kafetéi, kafetéye, kafetéyek (iz.): coffee shop / cafetería.

kafetéra, kafetérie, kafetérak (iz.): coffee maker / cafetera.

kajá, kajié, kájak (iz.): box / caja.

kajói, kajoyé, kajóyek (iz.): drawer / cajón.

kaká, kaká, kákak (iz.): excrement, shit / caca, mierda.

kaka (g)úre, kaka(g)úrie, kakagúriek (iz.): desire to defecate / ganas de cagar.

kaka(g)úrie euki du, kaka(g)úrie eukitzéu (ad.): to feel like defecating / tener ganas de cagar.

kakanáaste, kakanáastie, kakanáastiek (iz.): mess / lío.

kakanárru, kakanárrue, kakanárruek (izond.): dwarf, shorty / enano, pequeñajo.

kakaztú du, kakázteu (ad.): to spoil, to ruin / estropear.

kakáti, kakátiye, kakátiyek (izond.): 1. s.o. who defecates a lot; 2. fearful / 1. cagón; 2. miedoso.

kalabáza, kalabázie, kalabázak (iz.): pumpkin / calabaza. 
kalabáziñ, kalabáziñe, kalabáziñek (iz.): zucchini / calabacín.

kalé, kalié, kaliek (iz.): street / calle.

kaléndayo, kaléndayue, kaléndayuek (iz.): calendar / calendario.

kalentúra, kalentúrie, kalentúrak (iz.): fever / fiebre.

kalidáde, kalidádie, kalidádiek (iz.): quality / calidad.

káliz, kálize, kálizek (iz.): chalice / cáliz.

kalkáu du, kalkátzeu (ad.): to calque / calcar.

kalkuláu du, kalkulátzeu (ad.): to calculate / calcular.

kálkulo, kálkulue, kálkuluek (iz.): calculation, calculus / cálculo.

kalté (e)indú, kalté (e)itéu (ad.): to harm, to damage / dañar, perjudicar.

kalté, kaltié, kaltiek (iz.): harm, damage / daño, perjuicio.

kaltegárri, kaltegárriye, kaltegárriyek (izond.): harmful / dañoso, perjudicial.

kaltzetín, kaltzetíne, kaltzetínek (iz.): sock / calcetín.

kamaréra, kamarérie, kamarérak (iz.): female bartender / tabernera, camarera.

kamaréro, kamarérue, kamaréruek (iz.): male bartender/tabernero, camarero.

kamiói, kamióye, kamióyek (iz.): truck / camión.

kamixéta, kamixétie, kamixétak (iz.): t-shirt / camiseta.

kanál, kanalá, kanálak (iz.): canal; channel/canal.

kanbiázo, kanbiazúe, kanbiázuek (iz.): switch / cambiazo.

kánbiyo, kánbiyue, kánbiyuek (iz.): change / cambio.

kandéla, kandélie, kandélak (iz.): candle / candela, vela.

kánikatan ibilí da, kánikatan ibiltzeá (ad.): to play marbles / jugar a las canicas.

kánika, kánikie, kánikak ${ }^{6}$ (iz.): marble (ball) / canica.

kankárro, kankárrue, kankárruek (iz.): large metal container / recipiente grande de metal.

kanpái, kanpayé, kanpáyek (iz.): bell / campana.

kánpo, kánpue, kánpuek (iz.): outside / fuera.

kanposántu, kanposántue, kanposántuek (iz.): graveyard / cementerio, campo santo.

kánpotar, kánpotarra, kánpotarrak (izond.): stranger, outsider, foreigner / forastero, extranjero.

kantánte, kantántie, kantántiek (iz.): cantante / singer.

kantáu du, kantátzeu (ad.): to sing / cantar.

kantidáde, kantidádie, kantidádiek (iz.): quantity / cantidad.

kantói, kantoyé, kantóyek (iz.): lane, narrow street / cantón, callejón.

kantú, kantué, kantúek (iz.): song / canto, canción.

kántzer, kántzerra, kántzerrak (iz.): cancer / cáncer.

káña, káñie, káñak (iz.): fishing rod / caña de pescar.

kañói, kañoyé, kañóyek (iz.): 1. cannon; 2. canyon / 1. cañón (arma); 2. cañón, desfiladero.

kapáz, kapazá, kapázak (izond.): able / capaz.

kapilla, kapillie, kapillak (iz.): chapel / capilla. 
kapitáñ kapitáñe, kapitáñek (iz.): captain / capitán.

karakól, karakóla, karakólak (iz.): snail / caracol.

karamélo, karamélue, karaméluek (iz.): caramel, candy / caramelo.

kardáu du, kardátzeu (ad.): to card (fibers) / cardar.

kardáu, kardaué, kardáuek (iz.): carded (fiber) / cardado.

karé, karié, kariek (iz.): 1. lime (mineral); 2. plaster / 1. cal; 2. escayola.

kargaménto, kargaméntue, kargaméntuek (iz.): load / cargo, cargamento.

kargáu du, kargátzeu (ad.): to load / cargar.

kargú, kargué, kargúek (iz.): charge, responsibility / cargo, responsabilidad.

karidáde, karidádie, karidádiek (iz.): charity / caridad.

karnabál, karnabálak (iz.): carnival / carnaval(es).

karnét, karnetá, karnétak (iz.): identification card / carnet.

karnizéi, karnizéye, karnizéyek (iz.): butcher's / carnicería.

karnizéro, karnizérue, karnizéruek (iz.): butcher / carnicero.

karpéta, karpétie, karpétak (iz.): folder / carpeta.

karramárro, karramárrue, karramárruek (iz.): crab / cangrejo.

karrerá, karrerié, karrérak (iz.): 1. career; 2. degree / 1. carrera (laboral); 2. carrera (universitaria).

kartá, kartié, kártak (iz.): letter / carta.

kartél, kartelá, kartélak (iz.): poster / cartel.

karteléra, kartelérie, kartelérak (iz.): billboard (in a movie theater) / cartelera.

kartéra, kartérie, kartérak (iz.): wallet / cartera.

karteró, karterúe, kartéruek (iz.): mailman / cartero.

kartói, kartoyé, kartóyek (iz.): cardboard / cartón.

kartutxéra, kartutxérie, kartutxérak (iz.): pencil case / estuche.

kártzela, kártzelie, kártzelak (iz.): jail / cárcel.

kaséta, kasétie, kasétak (iz.): small house, hut / caseta.

kaskarréko, kaskarrékue, kaskarrékuek (iz.): blow on the head / golpe en la cabeza.

kásko, káskue, káskuek (iz.): helmet / casco.

kasó (e)iñ, kasó (e)itéu (ad.): pay attention / hacer caso.

kastañá, kastañie, kastáñak ${ }^{7}$ (iz.): chestnut / castaña.

kastigáu du, kastigátzeu (ad.): to punish / castigar.

kastígo, kastígue, kastíguek (iz.): punishment / castigo.

kásu, kásue, kásuek (iz.): case / caso, incidente.

kasualídade, kasualídadie, kasualídadiek (iz.): casuality / casualidad.

katakúme, katakúmie, katakúmiek (iz.): kitten / gatito.

katé, katié, katíek (iz.): chain / cadena.

káte, kátie, kátiek (iz.): failing grade / suspenso.

kateáu du, kateátzeu (ad.): to flunk an exam / suspender (un examen).

kategóri, kategóriye, kategóriyek (iz.): category / categoría.

7 kaztáña, kaztáñie, kaztáñak azentudun formak ere erabiltzen dira. 
kategóriko, kategórikue, kategórikuek (izond.): elegant, first class (often with irony) I de categoría.

katillú, katillúe, katílluek (iz.): bowl / tazón.

katú, katué, katúek (iz.): cat / gato.

káxkara, káxkarie, káxkarak (iz.): egg shell / cáscara.

káyola, káyolie, káyolak (iz.): cage / jaula.

kazuéla, kazuélie, kazuélak (iz.): cooking pot / cacerola, cazuela.

ke, kié, kiek (iz.): smoke / humo.

keixá, kéixak (iz.): cherry / cereza.

kejá, kejié, kéjak (iz.): complaint / queja.

kejáu da, kejátzea (ad.): to complain / quejarse.

kejíka, kejíkie, kejikak (izond.): complainer / quejica.

kendú du, kéntzeu (ad.): to take away / quitar.

kénketa, kénketie, kénketak (iz.): subtraction / resta, sustracción.

kilimá, kilimá, kilímak (iz.): tickle / cosquillas.

kílo, kílue, kíluek (iz.): kilogram / kilo.

kilómetro, kilómetrue, kilómetruek (iz.): kilometer / kilómetro.

kinkirriñin (adb.): to walk on one foot / andar saltando sobre un pie.

kinta, kintie, kintak (iz.): draft, levy, age / quinta. E. g.: 'nere kintakue' / 'of my same age' / 'de mi quinta'.

(ta) kitto (adb.): period, that's it / y se acabó.

kiñú, kiñué, kiñúek (iz.): wink, sign / guiño.

klarión, klarióna, klariónak (iz.): chalk / tiza.

kláro (interj.): of course / claro, por supuesto.

kláse, klásie, klásiek (iz.): 1. class, type; 2. class(room) / 1. clase, tipo; 2. clase, aula.

klasifíkadore, klasifíkadorie, klasifíkadorie (iz.) : classifier / clasificador.

klinika, klinikie, klínikak (iz.): clinic / clínica.

kobárde, kobárdie, kobárdiek (izond.): coward / cobarde.

kobazúlo, kobazúlue, kobazúluek (iz.): cave / cueva.

kobradóre, kobradórie, kobradóriek (iz.): collector / cobrador.

kobráu du, kobrátzeu (ad.): to receive or collect a payment / cobrar.

kointzidéntzi, kointzidéntziye, kointzidéntziyek (iz.): coincidence / coincidencia.

kointzidiu du, kointziditzeu (ad.): to coincide / coincidir.

kojiñ kojiñé, kojiñek (iz.): pillow / cojín.

kolá, kolié, kólak (iz.): 1. row, line, queue; 2. glue / 1. cola, fila; 2. cola de pegar.

koléta, kolétie, kolétak (iz.): ponytail / coleta, cola de cabello (peinado).

kolezíyo, kolezíyue, kolezíyuek (iz.): colection / colección.

kollaré, kollarie, kollárak (iz.): necklace / collar.

koloré, koloríe, kolóriek (iz.): color / color.

koltxói, koltxoyé, koltxóyek (iz.): matress / colchón.

komentáu du, komentátzeu (ad.): to comment / comentar.

koméntayo, koméntayue, koméntayuek (iz.): comment / comentario.

komíki, komíkiye, komíkiyek (iz.): comic / cómic, tebeo.

komodídade, komodídadie, komodídadiek (iz.): comfort / comodidad.

kómodo, kómodue, kómoduek (izond.): comfortable / cómodo.

komunídade, komunídadie, komunídadiek (iz.): community / comunidad. 
konbeniéntzi, konbeniéntziye, konbeniéntziyek (iz.): convenience / conveniencia. konbentziu du, konbentzitzeu (ad.): to convince / convencer.

konbertsáziyo, konbertsáziyue, konbertsáziyuek (iz.): conversation / conversación. kónde, kóndie, kóndiek (iz.): count (nobleman) / conde.

kondéna, kondénie, kondénak (iz.): sentence, conviction / condena.

kondenáu du, kondenátzeu (ad.): to condemn / condenar.

kondésa, kondésie, kondésak (iz.): countess / condesa.

kondizíyo, kondizíyue, kondizíyuek (iz.): condition / condición.

konduzíu du, konduzitzeu edo txofertú du, txofértzeu (ad.): to drive / conducir.

konferéntzi, konferéntziye, konferéntziyek (iz.): conference, talk / conferencia.

konfesáu du, konfesátzeu (ad.): to confess / confesar.

konfesiónayo, konfesiónayue (iz.): confessional box / confesionario.

konfesíyo, konfesíyue, konfesíyuek (iz.): confession / confesión.

konfiántza, konfiántzie, konfiántzak (iz.): trust, confidence / confianza.

konfiáu du, konfiátzeu (ad.): to trust / confiar.

konformáu da, konformátzea (ad.): to comform / conformar(se).

konjugáu du, konjugátzeu (ad.): to conjugate; conjugar.

konjugáziyo, konjugáziyue, konjugáziyuek (iz.): conjugation / conjugación.

konparáu du, konparátzeu (ad.): to compare / comparar.

konparáziyo, konparáziyue, konparáziyuek (iz.): comparison / comparación.

konpás, konpasá, konpásak (iz.): 1. compass; 2. time, rhythm (music) / compás (instrumento o de música).

konplikáu du, konplikátzeu (ad.): to complicate, to get complicated / complicar(se).

konplikáu, konplikáue, konplikáuek (izond.): complicated, complex / complicado, complejo.

konplikáziyo, konplikáziyue, konplikáziyuek (iz.): complication / complicación.

kónplize, kónplizie, kónpliziek (iz.): accomplice / cómplice.

konplót, konplotá, konplótak (iz.): plot / complot.

konpondú du, konpóntzeu (ad.): to fix / componer, arreglar, solucionar.

konpónketa, konpónketie, konpónketak (iz.): fixing / arreglo.

konportámento, konportámentue, konportámentuek (iz.): behavior / comportamiento.

konpostúra, konpostúrie, konpostúrak (iz.): composure / compostura.

konprométiu da, konprométitzea (ad.): to compromise / comprometer.

konpromiso, konpromisue, konpromísuek (iz.): engagement / compromiso.

konsegíu du, konsegitzeu edo lortú du, lórtzeu (ad.): to reach, to achieve / conseguir, alcanzar.

konsejéro, konsejérue, konsejéruek edo kontzejéro, kontzejérue, kontzejéruek (iz.): advisor / consejero.

konsejú, konsejúe, konséjuek (iz.): advice / consejo.

konsultáu du, konsultátzeu (ad.): to consult / consultar.

konsúlta, konsúltie, konsúltak (iz.): consultation / consulta.

kontajiáu du/da, kontajiátzeu/kontajiátzea (ad.): to infect, to transmit an illness / contagiar(se).

kontajióso, kontajiósue, kontajiósuek (izond.): contagious / contagioso.

kontáu du, kontátzeu (ad.): to tell a story / contar. 
kontestáu du, kontestátzeu edo erantzún du, erantzúteu (ad.): to reply, to answer / contestar.

kontestói, kontestóye, kontestóyek (izond.): cheeky, insolent (male) / contestón, respondón. kontestóna, kontestónie, kontestónak (iz.): cheeky, insolent (female) / respondona.

kóntra (Posp): against / contra. E. g.: 'dánok nere kóntra zaudete' / 'you are all against me'. kóntrako, kóntrakue, kóntrakuek (izond.): contrary / opuesto, contrario.

kontrastáu du, kontrastátzeu (ad.): to contrast / contrastar.

kontráste, kontrástie, kontrástiek (iz.): contrast / contraste.

kontratáu du, kontratátzeu (ad.): to hire / contratar.

kontrátu, kontrátue, kontrátuek (iz.): contract / contrato.

kontról, kontrolá, kontrólak (iz.): 1. control; 2. exam / 1. control; 2. control (examen). kontroláu du, kontrolátzeu (ad.): to control / controlar.

kontú, kontué, kontúek (iz.): 1. bill; account; 2. topic / 1. cuenta, facture; 2. asunto, tema.

kontúlai, kontúlaye, kontúlayek (izond.): s.o. who likes to tell stories / que cuenta cuentos. kontzejál, kontzejála, kontzejálak (iz.): town councillor / concejal.

kontziéntzi, kontziéntziye, kontziéntziyek (iz.): conscience / conciencia.

kontziérto, kontziértue, kontziértuek (iz.): concert / concierto.

kontzoláu du, kontzolátzeu (ad.): to console / consolar.

kontzoláziyo, kontzoláziyue, kontzoláziyuek (iz.): consolation / consolación, consuelo. kopá, kopié, kópak (iz.): drink (alcoholic); drinking glass / copa, trago.

kopetá, kopetíe, kopétak (iz.): forehead / frente.

kópi, kópiye, kópiyek (iz.): copy / copia.

kopiáu du, kopiátzeu (ad.): to copy / copiar.

korapillo, korapillue, korapílluek (iz.): knot / nudo.

korbáta, korbátie, korbátak (iz.): tie / corbata.

koró, korué, korúek (iz.): choir / coro.

koróna, korónie, korónak (iz.): crown / corona.

korrejíu du, korrejítzeu edo zuzendú du, zuzéntzeu (ad.): to correct / corregir.

korrespóndentzi, korrespóndentziye, korrespóndentziyek (iz.): correspondence / correspondencia.

korrespóndiu du, korrespónditzeu (ad.): to correspond / corresponder.

korriénte, korriéntie, korriéntiek (iz.): current / corriente (de agua, de electricidad, de aire). korrikálai, korrikálaye, korrikálayek (iz.): runner / corredor.

korroská, korroskáye, korróskak (iz.): burp / eructo.

kortina, kortínie, kortínak (iz.): courtain / cortina.

kortxéte, kortxétie, kortxétiek (iz.): bracket / corchete.

kórtxo, kórtxue, kórtxuek (iz.): cork / corcho.

kostá, kostié, kóstak (iz.): coast / costa.

kostáu da, kostátzea (ad.): to cost / costar.

kostílla, kostíllie, kostíllak (iz.): rib / costilla.

kottáu, kottáue, kottáuek (izond.): poor guy / pobre.

kótxe, kótxie, kótxiek (iz.): car / coche.

koxkortú da, koxkórtzea (ad.): to grow (a child) / crecer (los niños sobre todo).

kozináu du, kozinátzeu (ad.): to cook / cocinar.

koziñéra, koziñérie, koziñérak (iz.): cook (female) / cocinera. 
koziñéro, koziñérue, koziñéruek (iz.): cook (male) / cocinero.

krakatéko, krakatékue, krakatékuek (iz.): crack / crujido.

kriadá, kriadie, kriádak ${ }^{8}$ (iz.): maid / criada.

kriáu, kriáue, kriáuek (iz.): servant (male) / criado.

krimen, krimena, krimenak (iz.): crime / crimen.

kriminál, kriminála, kriminálak (izond.): criminal / criminal.

kristál, kristalá, kristálak ${ }^{9}$ (iz.): crystal, glass / cristal.

kristáu, kristaué, kristáuek (izond.): Christian / cristiano.

kritika, kritikie, kritikak (izond.): critic (female) / crítica.

kritika, kritikie, krítikak (iz.): criticism / crítica.

kritikáu du, kritikátzeu (ad.): to criticize / criticar.

kritiko, kritikue, kritikuek (izond.): critic (male) / crítico.

krixtona, krixtonak (izond.): huge / enorme.

krómo, krómue, krómuek (iz.): card (e.g. baseball) / cromo.

krúze, krúzie, krúziek (iz.): intersection / cruce de caminos.

kruzifikau du, kruzifíkatzeu (ad.): to crucify / crucificar.

kuadérno, kuadérnue, kuadérnuek (iz.): notebook / cuaderno.

kuádro, kuádrue, kuádruek (iz.): picture / cuadro.

kuartél, kuartelá, kuartélak (iz.): barracks / cuartel.

kúlpa, kúlpie, kúlpak (iz.): guilt / culpa.

kulpáble, kulpáblie, kulpábliek (izond.): guilty / culpable.

kumé, kumié, kumiék (iz.): offspring of an animal / cría de animal.

kumún, kumuné, kumúnek (iz.): toilet, bathroom / cuarto de baño, W. C.

kumuníyo, kumuníyue, kumuníyuek (iz.): communion / comunión.

kupél, kupelá, kupélak (iz.): barrel / tonel, cuba.

kupói, kupoyé, kupóyek (iz.): coupon / cupón.

kúrba, kúrbie, kúrbak (iz.): curve, bend / curva, revuelta.

kuriósa, kuriósie, kuriósak (izond.): curious (female) / curiosa.

kuriosídade, kuriosídadie, kuriosídadiek (iz.): curiosity / curiosidad.

kurióso edo kurióxo (adb.): orderly / ordenado, curiosamente. E. g.: dana kurioso-

kurioso utzi erten aurretik, $e$ ? 'leave everything ordered before going out' / 'déjalo toda bien ordenado antes de salir, ¿'eh?'.

kurióso, kuriósue, kuriósuek edo kurióxo, kurióxue, kurióxuek (izond.): curious (male) / curioso.

kursíllo, kursíllue, kursílluek edo kurtzíllo, kurtzíllue, kurtzílluek (iz.): short course, seminar / cursillo.

kúrtzo, kúrtzue, kúrtzuek (iz.): course / curso.

kutxará, kutxarie, kutxárak (iz.): spoon / cuchara.

kutxílla, kutxíllie, kutxíllak (iz.): razor / cuchillas (de afeitar).

kutxillo, kutxillue, kutxílluek (iz.): knife / cuchillo.

8 Hitz honek kriáda, kriádie, kriádak formak ere onartzen ditu, gaztelania kutsua egotzita.

9 kristelá, kristélak formak ere erabiltzen dira. 


\section{L}

la (g)ún, la (g)uné, la (g)únek (iz.): friend / amigo, -a.

la (g)undú du, lagúntzeu (ad.): 1. to help; 2. to accompany / 1. ayudar; 2. acompañar.

la(g)úntza, la (g)úntzie, la (g)úntzak (iz.): help / ayuda.

lababó, lababúe, labábuek ${ }^{10}$ (iz.): washing sink / lavabo.

labadóra, labadórie, labadórak (iz.): washing machine / lavadora.

labáñ, labañé, labáñek (izond.): slippery / resbaladizo.

labé, labié, labiek (iz.): oven / horno.

laburtú du, labúrtzeu (ad.): to shorten / acortar.

laguntzálle, laguntzállie, laguntzálliek (iz.): helper, assistant / ayudante.

láiñ (adb.): enough; able, capable / tanto como, suficiente; capaz.

laixté(r) (adb.): soon / pronto, en seguida.

láka, lákie, lákak (iz.): hair-spray / laca de pelo.

lan, laná, lának (iz.): work / trabajo.

lanbró, lanbrué, lanbrúek (iz.): drizzle, mist / bruma, llovizna.

landaré, landarie, landárak (iz.): plant / planta.

lánpara, lánparie, lánparak (iz.): lamp / lámpara.

lañó, lañué, lañúek (iz.): cloud / nube.

lañotú du, lañótzeu (ad.): to fog up / caer la niebla, nublarse.

lápa, lápie, lápak (iz.): limpet / lapa.

lapikó, lapikúe, lapíkuek (iz.): cooking pot / cazuela, olla.

lapúr, lapurré, lapúrrek (iz.): thief / ladrón.

lapurréta, lapurrétie, lapurrétak (iz.): theft, robbery / robo.

lapurtú du, lapúrtzeu (ad.): to steal / robar.

laréun (zenb.): four hundred / cuatrocientos.

larogéi (zenb.): eighty / ochenta.

larritásun, larritásune, larritásunek (iz.): predicament / apuro.

larritú da, larritzea (ad.): to get worried / preocuparse, apurarse.

larrosá, larrosíe, larrósak (iz.): rose / rosa.

lasái (adb.): calmly / tranquilamente.

lasái-lasái (adb.): calmly / con sosiego, calmosamente.

lasái, lasáye, lasáyek (izond.): calm, relaxed / tranquilo.

lasaitásun, lasaitásune, lasaitásunek (iz.): calm / tranquilidad.

lasaitú du/da, lasáitzeullasáitzea (ad.): to become quite, to calm down / calmar(se), tranquilizar(se).

lastó, lastué, lastúek (iz.): hey, straw / paja, heno.

láta, látie, látak (iz.): can / lata.

latá, latié, látak (iz.): (colloq.) hassle, bother, nuisance / (coloq.) lata, chapa.

latín, latiñé, latínek (iz.): Latin / latín.

látz, latzá, látzak (izond.): cool / guay.

10 Hitz honek baimentzen ditu labábo, labábue formak ere, gaztelania kutsua izanik ordea. 
lau (zenb.): four / cuatro.

lau ánkatan (adb.): crawling / a cuatro patas, gateando.

lauburú, lauburúe, laubúruek (iz.): Basque cross / cruz vasca.

legé, legié, legiek (iz.): law / ley.

lejía, lejía, lejíak (iz.): bleach / lejía.

lekutá (adb.): to a far away place / a un sitio lejano. E.g.: Japoneaño nai dezu jun? Le-

kutá zuez! 'You want to go to Japan? You are going far, boy!' / ‘¿quieres ir a Japón? ¡vas lejos, muchacho!'.

lekziyó, lekzíyúe, lekzíyuek (iz.): lesson / lección.

lélen (adb.): firstly / primeramente.

lélengo (adb.): firstly / primeramente.

lélengo, lélengue, lélenguek edo lélen, lélena, lélenak (izond.): first / primero (ordinal).

léngusu, léngusue, léngusuek (iz.): female/male cousin / primo, -a.

len (adb.): before / antes.

lentéja, lentéjie, lentéjak (iz.): lentil / lenteja.

lenúotik (adb.): since before / desde antes.

leór, leorrá, leórrak (izond.): dry / seco-a.

leórte, leórtie, leórtiek (iz.): drought / sequía.

leortúte (izond.): dry / seco.

lepo (zenbtz.): much, many, a lot / un montón.

létra, létrie, létrak (iz.): letter (character), handwriting / letra.

letú du, létzeu (ad.): to read / leer.

letxúga, letxúgie, letxúgak (iz.): lettuce / lechuga.

léyo, léyue, léyuek (iz.): window / ventana.

liáu dulda, liátzeulliátzea (ad.): to tangle, to get tangled / enredar(se).

líbra, líbrie, líbrak (iz.): pound (weight) / libra.

libráu da, librátzea (ad.): to free / librarse.

líbre, líbrie, líbriek (izond.): free / libre.

libréta, librétie, librétak (iz.): account book / libreta de ahorro.

líburu, líburue, líburuek (iz.): book / libro.

lija, lijie, lijak (iz.): sandpaper / lija.

lijáu du, lijátzeu (ad.): to sand / lijar.

likoré, likoríe, likóriek (iz.): liquor / licor.

limá, limié, límak (iz.): file (tool) / lima.

limáu du, limátzeu (ad.): to file / limar.

limói, limoyé, limóyek (iz.): lemon / limón.

lista, lístie, listak (izond.): smart, clever (female) / lista.

listá, listié, listak (iz.): list / lista.

listo, listue, listuek (izond.): smart, clever (male) / listo.

litro, litrue, litruek (iz.): liter / litro.

lixó, líxue, líxuek (izond.): flat / lisa, llano.

lixotú du, lixótzeu (ad.): to flatten / allanar.

lixto (adb.): ready / listo, dispuesto.

liztór, liztorrá, liztórrak (iz.): wasp / avispa.

llabéro, llabérue, llabéruek (iz.): key chain / llavero.

lo (e) in du, lo (e)itéu (ad.): to sleep / dormir. 
lo $(g)$ urá, lo(g)urie, lo $(g)$ úriek (iz.): sleepiness / sueño, ganas de dormir.

lokarrí, lokarríye, lokárriyek (iz.): string / cordón.

lokátz, lokátza, lokátzak (iz.): mud, clay / barro, lodo.

loló ein du, loló éiteu (ad.): to sleep (baby talk) / dormir (lenguaje infantil).

lorá, lorié, lórak (iz.): flower / flor.

lóro, lórue, lóruek (iz.): parrot / loro.

lortú du, lórtzeu (ad.): to achieve, to obtain / conseguir.

loterí, loteríye, loteríyek (iz.): lotery / lotería.

lóti, lótiye, lótiyek (izond.): sleepy / dormilón.

lotú du, lótzeu (ad.): to tie / atar.

lotzá, lotzié, lótzak (iz.): shame / vergüenza.

lotzagábe, lotzagábie, lotzagábiek (izond.): shameless / descarado, desvergonzado.

lotzagábekei, lotzagábekeye, lotzagábekeyek (iz.): shamelessness / insolencia, falta de respeto.

lotzagárri, lotzagárriye, lotzagárriyek (izond.): shameful / vergonzoso.

lotzáti, lotzátiye, lotzátiyek (izond.): shy / tímido.

lotzáu du/da, lotzátzeu/lotzátzea (ad.): to be shameful / avergonzar(se).

lújo, lújue, lújuek (iz.): luxury / lujo.

lujosó, lujosúe, lujósuek ${ }^{11}$ (izond.): luxurious / lujoso.

lumá, lumié, lúmak (iz.): feather / pluma de ave.

lúpa, lúpie, lúpak (iz.): magnifying glass / lupa.

lur, lurré, lúrrek (iz.): land / tierra.

lurrún, lurruné, lurrúnek (iz.): steem / vapor.

lúto, lútue, lútuek (iz.): mourning / luto.

luzarúen (adb.): for a long time / por largo tiempo.

luzáu da, luzátzea (ad.): to lengthen / alargar.

luzé, luzié, luziék (izond.): long / largo.

luzéra, luzérie, luzérak ${ }^{12}$ (iz.): length / largura, longitud.

\section{M}

madaléna, madalénie, madalénak (iz.): muffin / magdalena.

madaríkau, madaríkaue, madaríkauek (izond.): dammed / maldito/a.

madrigéra, madrigérie, madrigérak (iz.): den / madriguera.

madriléña, madriléñie, madriléñak (izond.): Madridian (female) / madrileña.

madriléño, madriléñue, madriléñuek (izond.): Madridian (male) / madrileño.

madrugádore, madrugádorie, madrugádoriek (izond.): early-riser / madrugador/a.

mágo, mágue, máguek (iz.): magician / mago.

mái, mayé, máyek (iz.): table / mesa.

11 Hitz honek baimentzen ditu lujóso, lujósue formak ere.

12 Aurreko belaunaldietan azentuazio aldaketa dago, hots, lúzera, lúzerie, lúzerak. 
maiátz, maiatzá, maiátzak (iz.): May / mayo. maitasún, maitasúne, maitasúnek (iz.): love / amor. máixu, máixue, máixuek (iz.): male teacher / maestro. mája, májie, májak (izond.): 1. nice (female); 2. good-looking (female) / 1. maja, simpática; 2. (mujer) de apariencia favorecida. májia, májia, májiak (iz.): magic / magia. májiko, májikue, májikuek (izond.): magical / mágico. májo, májue, májuek (izond.): 1. nice (male); 2. good-looking (male) / 1. majo, simpatico; 2. (hombre) de apariencia favorecida. makál-makál (adb.): slowly / lentamente. makál, makalá, makálak (izond.): slowmoving / lento/a. makaldú du, makáltzeu (ad.): to slow down / ir a menos, menguar. makárroi, makárroye, makárroyek (iz.): macaroni / macarrón. makéta, makétie, makétak (iz.): model / maqueta. makíl, makillé, makíllek (iz.): stick / palo. mákina, mákinie, mákinak (iz.): machine / máquina. makinista, makinistie, makinistak (iz.): machinist / maquinista. makurtú da, makúrtzea (ad.): to bend / agacharse, encogerse. makurtúte (adb.): bent / agachado, encorvado. malabárista, malabáristie, malabáristak (iz.): juggler/ malabarista. maledúkada, maledúkadie, maledúkadak (izond.): ill-behaved (female) / maleducada. maledúkau, maledúkaue, maledúkauek (izond.): ill-behaved (male) / maleducado. maléta, malétie, malétak (iz.): suitcase / maleta. maletin, maletiñe, maletiñek (iz.): briefcase / maletín. malizi, maliziye, maliziyek (iz.): malice / malicia. málla, mállie, mállak (iz.): level / nivel. mamí, mamiyé, mamíyek (iz.): 1. curd; 2. (bread) crumb / 1. cuajada; 2. miga (de pan). mamú, mamué, mamúek (iz.): ghost / fantasma.

mándo, mándue, mánduek (iz.): remote control / mando (de televisión). mandó, mandué, mandúek (iz.): mule / mula. manejáu du/da, manejátzeu/manejátzea (ad.): 1. to opérate; 2. to manage / 1. manejar; 2. arreglarse, manejarse. manejó, manejúe, manéjuek (iz.): skill / habilidad, manejo. mangéra, mangérie, mangérak (iz.): hose / manguera. mángo, mángue, mánguek (iz.): mango / mango. máni, mániye, mániyek (iz.): dislike, whim / manía. maniféstaziyo, maniféstaziyue, maniféstaziyuek (iz.): demonstration / manifestación. maniki, manikiye, manikiyek (iz.): mannequin / maniquí. manikúra, manikúrie, manikúrak (iz.): manicure / manicura. mánta, mántie, mántak (iz.): blanket / manta. mantál, mantalá, mantálak (iz.): apron / delantal, mandil. mantekilla, mantekillie, mantekillak (iz.): butter / mantequilla. manteníu du/da, mantenitzeu/mantenitzea (ad.): top support / mantener(se). mantzó-mantzó (adb.): slowly / lentamente.

mantzó, mantzué, mantzúek (izond.): tame, gentle / manso/a, dócil. manuál, manuála, manuálak (iz.): manual / manual. 
mápa, mápie, mápak (iz.): map / mapa.

maréa, maréie, maréak (iz.): tide / marea.

mareáu da, mareátzea (ad.): to get dizzy / marearse.

maréo, maréue, maréuek (iz.): confusion, bewilderment / aturdimiento.

marimútil, marimútille, marimútillek (izond.): tomboy / marimacho.

mariñél, mariñéla, mariñélak (iz.): sailor / marinero.

márka, márkie, márkak (iz.): 1. mark; 2. grief, mishap / 1. señal, marca; 2. disgusto.

markáu du, markátzeu (ad.): to mark / marcar.

márko, márkue, márkuek (iz.): frame / marco.

marmitáko, marmitákue, marmitákuek (iz.): tuna and potato dish / marmitako, un cocido hecho con bonito y patatas.

marrói, marroyé, marróyek (izond.): brown / marrón.

marróixka, marroixkie, marróixkak (izond.): brownish / amarronado.

marrubi, marrubiye, marrúbiyek (iz.): strawberry / fresa.

martíllo, martíllue, martílluek (iz.): hammer / martillo.

martxó, martxué, martxúek (iz.): March / marzo.

masá, masié, másak (iz.): dough / masa.

masáje, masájie, masájiek (iz.): massage, rub / masaje.

masajísta, masajístie, masajístak (iz.): masseur, masseuse / masajista.

masákre, masákrie, masákriek (iz.): masacre / masacre.

masifíkaziyo, masifíkaziyue, masifíkaziyuek (iz.): massification / masificación.

máskara, máskarie, máskarak (iz.): mask / máscara.

mastikáu du, mastikátzeu (ad.): to chew / masticar.

matadéro, matadérue, matadéruek (iz.): slaughterhouse / matadero.

materiál, materiála, materiálak (iz.): material / material.

matralléko, matrallékue, matrallékuek (iz.): slap (strong) / bofetada (fuerte).

matrimóniyo, matrimóniyue, matrimóniyuek (iz.): married couple; marriage / matri-

monio.

matté du, mattátzeu (ad.): to love / amar, querer.

matté, mattié, mattíek (izond.): beloved, dear / querido/a.

matxéte, matxétie, matxétiek (iz.): machete / machete.

matz, matzá, mátzak (iz.): grape / uva.

mayonésa, mayonésie, mayonésak (iz.): mayonnaise / mahonesa.

mayúskula, mayúskulie, mayúskulak (iz.): capital letter / letra mayúscula.

mazapán, mazapána, mazapának (iz.): marzipan / mazapán.

me, mié, miek (izond.): thin, narrow / estrecho/a, fino/a.

medidá, medidie, medídak (iz.): measurement / medida.

medikámentu, medikámentue, medikámentuek (iz.): medication / medicamento.

médiko, médikue, médikuek (iz.): physician / médico.

medizina, medizinie, medizinak (iz.): medicine, medication / medicina.

medúsa, medúsie, medúsak (iz.): jellyfish / medusa.

mejillói, mejillóie, mejílloiek (iz.): mussel / mejillón.

mekánika, mekánikie, mekánikak (iz.): mechanics / mecánica.

mekániko, mekánikue, mekánikuek (iz.): repair man / mecánico.

mekanísmo, mekanísmue, mekanísmuek (iz.): mechanism / mecanismo.

meléna, melénie, melénak (iz.): long hair / melena. 
melói, meloyé, melóyek (iz.): melon / melón.

membrillo, membrillue, membrilluek (iz.): quince / membrillo.

memóri, memóriye, memóriyek (iz.): memory / memoria.

memorizáu du, memoríatzeu (ad.): to memorize / memorizar.

mendi, mendiyé, mendíyek (iz.): mountain / monte, montaña.

menditóntor, menditóntorra, menditóntorrak (iz.): summit / cima del monte.

mendizále, mendizálie, mendizáliek (izond.): mountaineer / montañero, aficionado al monte.

mensáje, mensájie, mensájiek (iz.): message / mensaje.

merezi $d u$, merezitzeu (ad.): to deserve / merecer.

merezitako, merezitakue, merezitakuek ${ }^{13}$ (iz.): well-deserved punishment / merecido.

meriénda, meriéndie, meriéndak (iz.): snack / merienda.

mérito, méritue, mérituek (iz.): merit / mérito.

merké, merkié, merkíek (izond.): cheap / barato/a.

merketú du, merkétzeu (ad.): to lower the price / abaratar.

mermeláda, mermeládie, mermeládak (iz.): jam, marmelade / mermelada.

mesa nótxe, mesa nótxie, mesa nótxiek (iz.): night table / mesita de noche.

mesedé, mesedie, mesédiek (iz.): favor / favor.

mesilla, mesíllie, mesíllak (iz.): small table / mesilla.

metál, metalá, metálak (iz.): metal / metal.

metalézko, metalézkue, metalézkuek (izond.): metalic / metálico/a.

metáliko, metálikue, metálikuek (izond.): metalic / metálico/a.

metódiko, metódikue, metódikuek (izond.): methodical / metódico.

método, métodue, métoduek (iz.): method / método.

metralléta, metrallétie, metrallétak (iz.): machine gun / metralleta.

métro, métrue, métruek (iz.): meter / metro.

mezá, mezié, mézak (iz.): mass / misa.

mikátz, mikatzá, mikátzak ${ }^{14}$ (izond.): bitter / amargo/a.

milágro, milágrue, milágruek (iz.): miracle / milagro.

militár, militárra, militárrak (iz., izond.): military, soldier / militar.

millé (zenb.): a thousand / mil.

mimáu du, mimátzeu (ad.): to pamper / mimar.

mímo, mímue, mímuek (iz.): 1. fuss; 2. mime /1. mimo, afecto, caricia; 2. mimo (payaso). mina, minie, mínak (iz.): pencil lead / mina de lápiz.

mineró, minerúe, minéruek (iz.): miner / minero.

mingáñ, mingañé, mingáñek (iz.): tongue / lengua.

minimo, mínimue, mínimuek (izond.): minimum / mínimo.

minúskula, minúskulie, minúskulak (iz.): lower case letter / letra minúscula.

miñ hartú du, miñ hartzéu (ad.): to get hurt / hacerse daño.

miñ, miñé, miñek (iz.): pain / dolor.

13 mereziteko, merezitekue, merezítekuek formak ere erabiltzen dira.

14 mikétz, miketzá, mikétzak formak ere erabiltzen dira. 
misionéro, misionérue, misionéruek (iz.): missionary / misionero. misiyó, misiyúe, misíyuek (iz.): misión / misión. misto, mistue, mistuek (izond.): mixed / mixto. mixeráble, mixeráblie, mixerábliek (izond.): miserable / miserable. mixéri, mixériye, mixériyek (iz.): misery / miseria, pobreza. mo(b)imiénto, mo(b)imiéntue, mo(b)imiéntuek (iz.): movement / movimiento. mo(b)iú dulda, mo(b)itzeu/mo(b)itzea (ad.): to move / mover(se).

móda, módie, módak (iz.): fashion / moda.

modérna, modérnie, modérnak (izond.): modern (female) / moderna. modérno, modérnue, modérnuek (izond.): modern (male) / moderno. modísta, modistie, modistak (iz.): seamstress / modista. modórra, modórrie, modórrak (iz.): sleepiness / modorra, abotargamiento. modú, modué, modúek ${ }^{15}$ (iz.): manner / modo, manera. mokasin, mokasiñe, mokasiñek (iz.): moccasin / mocasín. mokó, mókue, mókuek (iz.): beak / pico. móko, mókue, mókuek (iz.): snot / moco. molestáu du, molestátzeu (ad.): to bother / molestar. molésti, moléstiye, moléstiyek (iz.): pain / molestia, dolor. moméntu, moméntue, moméntuek (iz.): moment / instante. monagíllo, monagíllue, monagílluek (iz.): altar boy / monaguillo. mónja, mónjie, mónjak (iz.): nun / monja. moratói, moratóye, moratóyek (iz.): bruise / moratón, cardenal. moráu, moráue, moráuek (izond.): purple / morado. moréna, morénie, morénak (izond.): dark, tanned (female) / morena (de tez y pelo). morenáu da, morenátzea (ad.): to get a tan, to become dark / ponerse moreno/a. moréno, morénue, morénuek (izond.): dark, tanned (male) / moreno. moskito, moskitue, moskituek (iz.): small flying bug / cualquier insecto volador pequeño. mósto, móstue, móstuek (iz.): grape juice / mosto.

mostradóre, mostradórie, mostradóriek (iz.): counter / mostrador. móstro, móstrue, móstruek (iz.): monster / monstruo. motél, motelá, motélak (izond.): 1. slow; 2. motel / 1. lento; 2. motel. moteldú da, motéltzea (ad.): to slow down / realentizarse. motór, motorrá, motórrak (iz.): 1. motorcycle; 2. engine / 1. motocicleta. 2. motor. motorísta, motorístie, motorístak (iz.): motorcycle driver / conductor de una moto. motxíla, motxílie, motxílak (iz.): backpack / mochila. motz, motzá, mótzak (izond.): short / corto/a. mozkór, mozkorrá, mozkórrak edo pédo, pédue, péduek (iz.): drunkness / borrachera. mozkortú da, mozkórtzea (ad.): to get drunk / emborracharse. moztú du, mózteu (ad.): to cut / cortar. mugá, mugié, múgak (iz.): boundary, frontier / frontera, muga. múlta, múltie, múltak (iz.): fine / multa.

15 Hitz honetan d>r aldaketa jazo daiteke; honela, morú, morué, morúek formak onartuz (Hualde \& Beristain, 2019). 
multáu du, multátzeu (ad.): to fine / multar.

multzó, multzué, multzúek (iz.): group, pile / grupo, montón.

mundú, mundué, mundúek (iz.): world / mundo.

munizipal, munizipala, munizípalak (izond.): 1. municipal; 2. (iz.) local policeman / 1.

municipal; 2. policía local.

mus, musé, músek (iz.): a card game / juego del mus.

músika, músikie, músikak (iz.): music / música.

músiko, músikue, músikuek (iz.): musician / músico.

mutíll, mutillé, mutíllek (iz.): boy / chico.

mutílzar, mutílzarra, mutílzarrak (izond.): old bachelor / solterón.

mutú, mutué, mutúek (izond.): mute / mudo.

mutúr, muturré, mutúrrek (iz.): snout / morro, hocico.

muturréko, muturrékue, muturrékuek (iz.): punch in the face / puñetazo.

muxú emán du, muxú emateu (ad.): to kiss / besar.

muxú, muxué, muxúek (iz.): kiss / beso.

muzkér, muzkerrá, muzkérrak (iz.): lizard / lagarto.

\section{$\mathrm{N}$}

nabegáziyo, nabegáziyue, nabegáziyuek (iz.): navigation; navegación.

nai béste (adb.): a lot, as much as one could desire / mucho, tanto como se quiera.

nái, nayé, náyek (iz.): desire, wish / deseo.

naikó edo naikué (adb., zenbtz.): enough, quite a few / bastante(s). E.g.: naikó gizon

etorri die gaur batzarrea 'quite a few men have come to the meeting today' / 'bastan-

tes hombres han venido a la reunión hoy'.

náita (adb.): on purpose / queriendo, aposta.

náizta (junt.): even though, although / aunque.

napár, naparrá, napárrak (izond.): Navarrese / navarro/a.

naránja, naránjie, naránjak (iz.): orange / naranja.

narradóre, narradórie, narradóriek edo narratzálle, narratzállie, narratzálliek (iz.): na-

rrator / narrador/a.

narrazíyo, narrazíyue, narrazíyuek (iz.): narration / narración.

narrutzík (adb.): naked / desnudo/a, en pelotas.

náste-bórraste, náste-bórrastie, náste-bórrastiek (iz.): mess / lío, confusión.

náste, nástie, nástiek (iz.): mixture, mess / mezcla, confusión, lío.

nastú du, násteu (ad.): to mix, to mix up / confundir, mezclar.

náta, nátie, nátak (iz.): cream / nata.

naturál, naturála, naturálak (izond.): natural / natural.

naximénto, naximéntue, naximéntuek (iz.): nativity scene / nacimiento, belén navideño.

nazionál, nazionála, nazionálak (izond.): national / nacional.

naziyó, naziyúe, nazíyuek (iz.): nation / nación.

$n e(g) a ́ r(e)$ in $d u, n e(g)$ ar (e)iteu (ad.): to cry / llorar.

ne(g)ár, ne(g)arrá, ne(g)árrak (iz.): weaping, tear / lágrima.

nebéra, nebérie, nebérak (iz.): icebox, refrigerator / nevera.

negárti, negártiye, negártiyek (izond.): cry-baby / llorón/a.

negoziáu du, negoziátzeu (ad.): to deal, to negotiate / negociar. 
negóziyo, negóziyue, negóziyuek (iz.): business / negocio.

negú, negué, negúek (iz.): winter / invierno.

nekáu da, nekátzea (ad.): to get tired, to tire / cansar(se).

neké, nekié, nekiek (iz.): tiredness, exhaustion / cansancio.

nekéz (adb.): painfully / penosamente.

nerbiósa, nerbiósie, nerbiósak (izond.): nervous (female) / nerviosa.

nerbióso jarri dá, nerbióso jartzeá (ad.): to become nervous / ponerse nervioso/a.

nerbióso, nerbiósue, nerbiósuek (izond.): nervous (male) / nervioso.

nérbiyo, nérbiyue, nérbiyuek (iz.): nerve / nervio.

neská, neskié, néskak (iz.): girl; young woman / niña; mujer joven.

neskázar, neskázarra, neskázarrak (iz.): spinster / solterona.

néurri, néurriye, néurriyek (iz.): measure / medida.

neurtú du, néurtzeu (ad.): to measure / medir.

nezezér, nezezérra, nezezérrak (iz.): toilet case / neceser.

nibél, nibelá, nibélak (iz.): level / nivel.

nibeláu du, nibelátzeu (ad.): to level / nivelar.

noá (gald.): where (to), whither / adónde.

noáiño (gald.): up to where / hasta dónde.

nobáta, nobátie, nobátak (izond.): beginner (female) / novata.

nobatáda, nobatádie, nobatádak (iz.): hazing of new member; beginner's mistake / novatada.

nobáto, nobátue, nobátuek (izond.): beginner (male) / novato.

nobéla, nobélie, nobélak (iz.): novel / novela.

nóbia, nóbiyie, nóbiak edo neská, neskié, néskak (iz.): girlfriend / novia.

nóbiyo, nóbiyue, nóbiyuek edo mutíl, mutillé, mutíllek (iz.): boyfriend / novio.

nóble, nóblie, nóbliek (izond.): noble, honest / noble, honrado/a.

noiz (adb.): when / cuándo.

nóiz árte (zenbtz.): until when / hasta cuándo.

noizbáit (zenbtz.): sometime / alguna vez.

noizín béiñ (adb.): from time to time / de vez en cuándo.

noizkó (gald.): for when / para cuándo.

noiztík (gald.): since when / desde cuándo.

nolá (gald.): how, in which manner / cómo, de qué manera.

nolakó, nolakúe (gald.): of which type / de que tipo o naturaleza.

noraézien (adb.): disoriented / desorientado/a.

norbeá (izord.): oneself / uno/a mismo/a.

normál, normalá, normálak (izond.): normal / normal.

normalien (adb.): generally, normally / normalmente.

nóta, nótie, nótak (iz.): grade / nota.

notáriyo, notáriyue, notáriyuek (iz.): notary public / notario.

notizi, notiziye, notiziyek (iz.): news / noticia.

número, númerue, númeruek (iz.): number / número.

nun (gald.): where / dónde.

nunbaitéa (zenbtz.): (to) somewhere / a algún sitio.

nunbaitén (zenbtz.): somewhere / en algún sitio.

nundík (gald.): from where; whence / de dónde. 


\section{$\tilde{\mathbf{N}}$}

ñabardura, ñabardurie, ñabardúrak (iz.): slight difference between two items / sutil diferencia entre dos objetos.

$\tilde{n}_{O}$ (interj.): exclamation of surprise / exclamación de sorpresa, ¡vaya!

\section{$\mathrm{O}$}

obé (adb.): better / mejor. E.g.: obé dezú etórtzie 'you have better come' / 'es mejor que vengas'.

obé, obié, obiek (izond.): better / mejor.

obedéziu du, obedézitzeu (ad.): to obey / obedecer.

obediénte, obediéntie, obediéntiek (izond.): obedient / obediente.

obéto (adb.): better / mejor.

obetú du, obétzeu (ad.): to improve / mejorar.

obligáu du, obligátzeu edo derriórtu du, derriórtzeu (ad.): to oblige / obligar.

obligáziyo, obligáziyue, obligáziyuek (iz.): obligation, task / obligación.

óbra, óbrie, óbrak (iz.): work, construction / obra.

obrerá, obrerie, obrérak (iz.): worker (female) / obrera.

obreró, obrerúe, obréruek (iz.): worker (male) / obrero.

obsesiónau da, obsesiónatzea (ad.): to be or become obsessed / estar obsesionado, obsesionarse.

obsesiyo, obsesíyue, obsesíyuek (iz.): obsession / obsesión.

odól, odolá, odólak (iz.): blood / sangre.

odolústu da, odolústea (ad.): to bleed, to lose a lot of blood / sangrar, desangrarse.

oé, oyé, óyek (iz.): bed / cama.

ofendiu du, ofenditzeu (ad.): to offend / ofender.

ofizina, ofizinie, ofizinak edo bulegó, bulegúe, buléguek (iz.): office / oficina.

ofizinista, ofizinistie, ofizinistak (iz.): office worker / oficinista.

ofiziyo, ofiziyue, ofiziyuek (iz.): job / oficio.

ogéi (zenb.): twenty / veinte.

ogí, ogiyé, ogíyek (iz.): bread / pan.

oi (interj.): what a / vaya, que. E.g.: oi mutill ona! 'what a good boy!' / ¡vaya qué niño más bueno!'

óiek (izord.): those / esos.

óindik (adb.): still / aún, todavía.

oingún (adb.): this time / esta vez.

óintxe (adb.): right now / ahora mismo.

ollótei, ollóteye, ollóteyek (iz.): henhouse / gallinero.

óin (adb.): now / ahora.

oiñárte (adb.): until now, hitherto / hasta ahora.

oitúra, oitúrie, oitúrak (iz.): custom / costumbre.

oitúta (pred. adj.): used to, accostumed / acostumbrado/a.

óixe (bea) (izord.): that very one / ese/a/o mismo/a.

ojáldre, ojáldrie, ojáldriek (iz.): puff pastry / hojaldre.

ojéra, ojérak (iz.): rings under the eyes / ojera. 
okasiyo, okasíyue, okasiyuek (iz.): ocassion / ocasión.

okér, okerrá, okérrak (izond.): twisted / torcido.

okertú du, okértzeu (ad.): to twist / torcer.

okótz, okotzá, okótzak (iz.): chin / barbilla.

okupáu du, okupátzeu (ad.): occupate / ocupar.

okupáziyo, okupáziyue, okupáziyuek (iz.): occupation / ocupación.

olakó, olakúe, olakúek: like this, such / tal, de esta calidad.

olató, olatúe, olátuek (iz.): wave / ola.

olaxé (adb.): in that manner (emphatic) / así mismito.

ólki, ólkiye, ólkiyek (iz.): blood-saussage / morcilla.

óllar, óllarra, óllarrak (iz.): rooster / gallo.

óllaxko, óllaxkue, óllaxkuek (iz.): chicken / pollo.

olló, ollué, ollúek (iz.): hen / gallina.

omenáje, omenájie, omenájiek (iz.): homage / homenaje.

on, oná, ónak (izond.): good/ buena.

ondár, ondarrá, ondárrak (iz.): sand / arena.

ondú(e)n (adb.): beside / al lado.

oneá (adb.): (to) here, hither / a aquí. E.g.: etorri oneá! 'come here!' / ‘ven aquí!

oneáño (adb.): up to here, hitherto / hasta aquí.

ónezkeo (adb.): already, now / ya, para ahora.

onoré, onorie, onóriek (iz.): honor / honor.

onradá, onradie, onrádak (izond.): honest (female) / honrada.

onráu, onraué, onráuek (izond.): honest (male) / honrado.

onútz (adb.): in this direction / hacia aquí.

oñéz (adb.): by foot / a pie.

ópera, óperie, óperak (iz.): opera / ópera.

operádore, operádorie, operádoriek (iz.): operator / operador.

operáu dulda, operátzeu/operátzea (ad.): to operate, to undergo surgery / operar(se).

opill, opillé, opillek (iz.): type of cake / torta parecida al pan.

opiniyo, opiníyue, opiníyuek (iz.): opinion / opinión.

oposiziyo, oposiziyue, oposiziyuek (iz.): opposition / oposición.

or (adb.): there / ahí.

órden, órdena, órdenak (iz.): order / orden, organización.

ordenádore, ordenádorie, ordenádorak (iz.): computer / ordenador, computadora.

ordenáu du, ordenátzeu (ad.): to arrange, to order / ordenar, arreglar.

ordezkó, ordezkúe, ordézkuek (iz.): replacement, substitute / sustituto.

ordú, ordué, ordúek (iz.): hour / hora.

orduérdi, orduérdiye, orduérdiyek (iz.): half an hour / media hora.

ordún (adb.): then / entonces.

ordundík (adb.): since then / desde entonces.

oreká, orekie, orékak (iz.): balance / equilibrio.

orgúllo, orgúllue, orgúlluek (iz.): pride / orgullo.

orgullósa, orgullósie, orgullósak (izond.): proud (female) / orgullosa.

orgullóso, orgullósue, orgullósuek (izond.): proud (male) / orgulloso.

orí (izord.): that / ese, esa, eso.

orí, oriyé, oríyek (izond.): yellow / amarillo. 
oritásun, oritásune, oritásunek (iz.): yellowness / paleness of face / amarillez, palidez en el rostro.

oritú da, oritzea (ad.): to become yellow / volverse amarillo. orixká, orixkie, orixkak (izond.): yellowish / amarillento.

orkilla, orkíllie, orkillak (iz.): hairpin / horquilla.

orkó (izord.): of there / de ahí.

orpó, orpué, orpúek (iz.): heel / talón.

orrátz, orratzá, orrátzak (iz.): needle / alfiler, aguja.

orrazi, orrazíye, orráziyek (iz.): comb / peine.

orrázkera, orrázkerie, orrázkerak (iz.): combing style / forma de peinarse.

orraztú du/da, orrázteu/orráztea (ad.): to comb / peinar(se).

orreá (adb.): there / ahí.

orréaño (adb.): up to there / hasta allí.

orrék (izord.): that, ERG / ese, ERG.

orretxéatik: because of that / por eso.

orrí, orriyé, orríyek (iz.): sheet of paper / hoja.

ortík (izord.): from there; around there / desde ahí; por ahí.

ortz, ortzá, órtzak (iz.): tooth / diente.

ortzaká, ortzakáye, ortzakáyek (iz.): biting / mordisco.

osasún, osasúne, osasúnek (iz.): health / salud.

osáu du, osátzeu (ad.): to complete / completar.

oséake (junt.): thus, therefore, so / o sea que.

osóik (adb.): completely / enteramente.

óspa (e)in du, óspa (e)iteu (ad.): to leave / largarse, irse.

ospáu du, ospátzeu (ad.): to celebrate / celebrar.

ospitál, ospitála, ospitálak (iz.): hospital / hospital.

ostál, ostalá, ostálak (iz.): hostel / hostal.

ostegún, ostegúne, ostegúnek (iz.): Thursday / jueves.

ostikáda, ostikádie, ostikádak (iz.): kick / patada.

ostirél, ostiréla, ostirélak (iz.): Friday / viernes.

ostó, ostué, ostúek (iz.): leaf / hoja de árbol.

oté (aurrizk.): modal prefix of doubt, perhaps / prefijo modal de duda, acaso.

otordú, otordúe, otórduek (iz.): meal / comida en general.

otz, otzá, ótzak (iz., adj.): cold / frío.

otzó, otzué, otzúek (iz.): wolf / lobo.

oxidáu da, oxidátzea (ad.): to rust / oxidar.

oztú du/da, ózteu/óztea (ad.): to get cold / refrescar, enfriar(se).

$\mathbf{P}$

paélla, paéllie, paéllak (iz.): paella / paella.

paelléra, paellérie, paellérak (iz.): paella pan / paellera.

pága, págie, págak (iz.): payment, allowance / paga.

pagáu du, pagátzeu (ad.): to pay / pagar.

pagó, pagué, pagúek (iz.): beech tree / haya (árbol).

págo, págue, páguek (iz.): payment / pago. 
paisáje, paisájie, paisájiek (iz.): landscape / paisaje. pajarita, pajaritie, pajaritak (iz.): bow tie / pajarita. páje, pájie, pájiek (iz.): page / paje.

pajita, pajitie, pajitak (iz.): drinking straw / pajita. paké, pakié, pakiek (iz.): peace / paz.

pakéte, pakétie, pakétiek (iz.): package / paquete.

pála, pálie, pálak (iz.): 1. shovel, spade; 2 . racquet / pala (de frontón y de cavar). palabróta, palabrótie, palabrótak (iz.): bad word / palabrota.

paladár, paladárra, paladárrak edo ahosápai, ahosápaye, ahosápayek (iz.): palate / paladar.

palánka, palánkie, palánkak (iz.): lever / palanca.

paláziyo, paláziyue, paláziyuek (iz.): palace / palacio.

paléta, palétie, palétak (iz.): front teeth / paletas.

palillo, palíllue, palílluek (iz.): toothpick / palillo.

paliza, palizie, palizak edo jipói, jipoyé, jipóyek (iz.): beating / paliza.

palméra, palmérie, palmérak (iz.): palm tree / palmera.

panadéi, panadéye, panadéyek (iz.): bread shop / panadería.

panadéra, panadérie, panadérak (iz.): female baker / panadera.

panadéro, panadérue, panadéruek (iz.): baker / panadero.

panderéta, panderétie, panderétak (iz.): tambourin / pandereta.

pandílla, pandíllie, pandíllak (iz.): gang / pandilla.

pankárta, pankártie, pankártak (iz.): banner / pancarta.

pantálla, pantállie, pantállak (iz.): screen / pantalla.

panteói, panteóye, panteóyek (iz.): pantheon / panteón.

pañál, pañalá, pañálak (iz.): diaper / pañal.

pañuélo, pañuélue, pañuéluek (iz.): handkerchief / pañuelo.

papadá, papadie, papádak (iz.): double chin / papada.

papár, paparrá, papárrak (iz.): breast, chest / parte superior del pecho.

papél, papelá, papélak (iz.): paper / papel.

papeléta, papelétie, papelétak (iz.): ticket / papeleta.

papérak (iz.): mumps / paperas (enfermedad).

papilla, papillie, papíllak (iz.): baby food / papilla.

paradója, paradójie, paradójak (iz.): paradox / paradoja.

paradójiko, paradójikue, paradójikuek (izond.): paradoxical / paradójico/a.

paráje, parájie, parájiek (iz.): place, spot / paraje.

parakáidas, parakáidasa, parakáidasak (iz.): parachute / paracaídas.

paréja, paréjie, paréjak (iz.): couple / pareja.

páro, párue, páruek (iz.): unemployment / paro, desempleo.

parránda, parrándie, parrándak (iz.): spree / juerga.

parré (e) in du, parré (e)itéu (ad.): to laugh / reir.

parré, parrié, parríek (iz.): smile / sonrisa.

párrezka (adb.): laughing / riendo.

parróki, parrókiye, parrókiyek (iz.): parish / parroquia.

párroko, párrokue, párrokuek (iz.): parish priest / párroco.

partzéla, partzélie, partzélak (iz.): land lot / parcela.

pasapórte, pasapórtie, pasapórtiek (iz.): passport / pasaporte. 
pasáu daldu, pasátzea/pasátzeu (ad.): 1. to happen; 2. to exceed; 3. to pass / 1. acontecer; 2. exceder(se), pasar(se); 3. pasar.

paseáu du, paseátzeu (ad.): to stroll / pasear.

pasíllo, pasillue, pasílluek (iz.): corridor / pasillo.

pastél, pastelá, pastélak (iz.): cake / pastel.

pasteléra, pastelérie, pastelérak (iz.): female confectioner / pastelera.

pasteléro, pastelérue, pasteléruek (iz.): male confectioner / pastelero.

pastílla, pastíllie, pastíllak (iz.): tablet / pastilla.

patatá, patatie, patátak (iz.): potato / patata.

patílla, patíllie, patíllak (iz.): sideburns / patilla.

patin, patiñé, patínek (iz.): skate / patin.

patináje, patinájie, patinájiek (iz.): skating / patinaje.

patináu du, patinátzeu (ad.): to skate / patinar.

pátiyo, pátiyue, pátiyuek (iz.): patio, yard / patio.

patrói, patroyé, patróyek (iz.): patron, boss / patrón.

pattár, pattarrá, pattárrak (iz.): brandy / aguardiente.

patxará, patxarie, patxárak (iz.): nonchalance / tranquilidad.

patxarán, patxarána, patxarának (iz.): type of brandy / pacharán.

pausó, pausué, pausúek (iz.): step / paso (de caminar).

paxíra jun da, paxíra juteá (ad.): do jogging / ir a pasear.

paxíra, paxírie, paxírak (iz.): stroll, walk / paseo.

payáso, payásue, payásuek (iz.): clown / payaso.

paziéntzi, paziéntziye, paziéntziyek (iz.): patience / paciencia.

pazifiko, pazifikue, pazifikuek (izond.): peaceful / pacífico.

peáje, peájie, peájiek (iz.): toll / peaje.

peatói, peatóye, peatóyek (iz.): pedestrian / peatón.

pegaménto, pegaméntue, pegaméntuek (iz.): glue / pegamento.

pegáu dulda, pegátzeu/pegátzea (ad.): to glue / pegar(se).

péka, pékie, pékak (iz.): freckle / peca.

pekatú, pekatúe, pekátuek (iz.): sin / pecado.

pelígro, pelígrue, pelígruek (iz.): danger / peligro.

peligróso, peligrósue, peligrósuek (izond.): dangerous / peligroso/a.

pelikula, pelikulie, pelíkulak (iz.): film / película.

pélma, pélmie, pélmak (izond.): bothersome, boring / pelma, pesado/a.

pélota, pélotie, pélotak (iz.): ball / pelota.

pelúka, pelúkie, pelúkak (iz.): wig / peluca.

pelukéi, pelukéye, pelúkeyek (iz.): hairdresser's / peluquería.

pelukéra, pelukérie, pelukérak (iz.): female hairdresser / peluquera.

pelukéro, pelukérue, pelukéruek (iz.): barber / peluquero.

pelusílla, pelusillie, pelusíllak (iz.): down, fuzz / pelusilla.

péna, pénie, pénak (iz.): regret, sadness / pena, compasión.

penagárri, penagárriye, penagárriyek (izond.): sad, regretful / penoso, triste.

pentzáu du, pentzátzeu (ad.): to think / pensar.

pentzaméntu, pentzaméntue, pentzaméntue (iz.): thought, thinking / pensamiento.

pentziyó, pentziyúe, pentzíyuek (iz.): pension / pensión.

pentzú, pentzué, pentzúek (iz.): fodder / pienso. 
peói, peóye, peóyek (iz.): laborer, unskilled worker / peón.

pepino, pepinue, pepinuek (iz.): cucumber / pepino.

perejíl, perejílle, perejillek (iz.): parsley / perejil.

perezá, perezie, perézak (iz.): laziness; pereza.

perilla, períllie, períllak (iz.): goatee / perilla.

periódiko, periódikue, periódikuek (iz.): newspaper / periódico.

perlá, perlié, pérlak (iz.): pearl / perla.

perretxíko, perretxíkue, perretxíkuek (iz.): mushroom / champiñón.

pértxa, pértxie, pértxak (iz.): hanger / percha.

pertxéro, pertxérue, pertxéruek (iz.): clothes rack / perchero.

pertzekúziyo, pertzekúziyue, pertzekúziyuek (iz.): persecution / acoso, persecución.

pertziána, pertziánie, pertziának (iz.): Venetian blind / persiana.

pertzóna, pertzónie, pertzónak (iz.): person / persona.

pertzonáje, pertzonájie, pertzonájiek (iz.): character / personaje.

peskadéro, peskadérue, peskadéruek (iz.): fish seller / pescadero.

pestáña, pestáñie, pestáñak (iz.): eyelash / pestaña.

petáka, petákie, petákak (iz.): cigarette case / petaca.

pétalo, pétalue, pétaluek (iz.): petal / pétalo.

petárdo, petárdue, petárduek (iz.): firecracker / petardo.

petxó, petxué, petxúek (iz.): chest, breast / pecho.

pexetéro, pexetérue, pexetérue edo xur, xurré, xúrrek (izond.): stingy / pesetero/a.

pezói, pezóye, pezóyek (iz.): nipple / pezón.

pijáma, pijámie, pijámak (iz.): pajamas / pijama.

pikadúra, pikadúrie, pikadúrak (iz.): sting / picadura, picotada.

pikéte, pikétie, pikétiek (iz.): picket / piquete.

pikoré, pikorie, pikoriek (iz.): itch / picor, escozor / acritud en la garganta.

pikú, pikué, pikúek (iz.): fig / higo.

píla, pílie, pílak (iz.): battery / pila.

pilláu da, pillátzea (ad.): to pile up / amontonarse, apilarse.

píllo bat edo mordúe (zenbtz.): a lot / un montón.

pilóto, pilótue, pilótuek (iz.): pilot / piloto.

pintáu du, pintátzeu (ad.): to paint / pintar.

pintoré, pintoríe, pintóriek (iz.): painter / pintor.

pinturá, pinturíe, pintúrak ${ }^{16}$ (iz.): paint / pintura.

pintxáu da, pintxátzea (ad.): to prick, to puncture / pinchar.

pintxazó, pintxazúe, pintxázuek (iz.): puncture / pinchazo.

pintzél, pintzelá, pintzélak (iz.): brush / pincel.

pintzeláda, pintzeládie, pintzeládak (iz.): stroke with a brush / pincelada.

piña, piñie, piñak (iz.): pineapple / piña.

piñói, piñoyé, piñóyek (iz.): pine-nut / piñón.

piñú, piñué, piñúek (iz.): pine tree / pino.

16 Hitz honek baimentzen ditu pintúra, pintúrie formak ere, gaztelania kutsua izanik ordea. 
pípa, pípie, pipak (iz.): 1. pipe; 2. sunflower seed / 1. pipa de fumar; 2. pipa (fruto seco). pipér, piperrá, pipérrak (iz.): pepper / pimiento.

piráta, pirátie, pirátak (iz.): pirate / pirata.

pista, pistie, pistak (iz.): track / pista (de atletismo).

pisto, pistue, pistuek (iz.): dish with tomatoes, cucumber and zucchini / revuelto de tomate, pepino y calabacín.

pitíllo, pitílluek (iz.): type of pants / pitillo (pantalones).

piurá, piurie, piúrak (iz.): slovenliness / hechura triste, malfigurado/a.

pixáu du, pixátzeu (ad.): to weigh / pesar.

píxkat (adb.): a little / un poco.

pixú, pixué, pixúek (iz.): 1. apartment; 2. weight / 1. piso; 2. peso.

pizina, pizinie, pizinak (iz.): swimming pool / piscina.

piztú du, piztea (ad.): to light / encender.

plága, plágie, plágak (iz.): plague / plaga.

plái, playé, pláyek (iz.): beach / playa.

pláka, plákie, plákak (iz.): plate / placa.

plan, planá, plának (iz.): plan / plan.

plantói, plantoyé, plantóyek (iz.): long wait / plantón.

plantxá, plantxié, plántxak (iz.): iron (for clothes) / plancha.

plantxáu du, plantxátzeu (ad.): to iron / planchar.

plásta, plástie, plástak (izond.): bothersome / plasta, pesado/a.

plástiko, plástikue, plástikuek (iz.): plastic / plástico.

plastilina, plastilínie, plastilinak (iz.): play dough / plastilina.

plateáu, plateáue, plateáuek (izond.): silver / plateado/a.

platér, platerá, platérak (iz.): plate, dish / plato.

platérak garbiuiitu, platérak garbitzeitu (ad.): to do the dishes / fregar los platos.

platíllo, platíllue, platílluek (iz.): cymbals / platillos (de orquesta).

plazá, plazié, plázak (iz.): square / plaza.

plazó, plázue, plázuek (iz.): term / plazo.

pléito, pléitue, pléituek (iz.): lawsuit / pleito.

póbre, póbrie, póbriek (izond.): poor / pobre, sin recursos.

pólbora, pólborie, pólborak (iz.): gunpowder / pólvora.

polborói, polboróye, polboróyek (iz.): type of cake / polvorón.

poliki (adb.): 1. carefully; 2. slowly / 1. cuidadosamente; 2 . despacio.

polítika, politikie, politikak (iz.): 1.politics; 2. politician (female) / política (ámbito + profesión).

politiko, politikue, politikuek (iz.): politician (male) / político.

politt, politté, polittek (izond.): pretty / bonito -a.

polizí, polizíye, polizíyek (iz.): police; policeman / policía.

pollerí, polleríye, polleríyek (iz.): chicken market / pollería.

pólo, pólue, póluek (iz.): 1. t-shirt; 2. icicle / 1. polo (camiseta); 2. polo helado.

poltxíko, poltxíkue, poltxíkuek (iz.): pocket / bolsillo.

poltzá, poltzié, póltzak (iz.): bag / bolsa.

porkerí, porkeríye, porkeríyek edo txerrikéi, txerrikéye, txerrikéyek (iz.): filth / porquería, suciedad.

porlán, porlaná, porlának (iz.): cement / cemento. 
póro, pórue, póruek (iz.): pore / poro (de la piel).

porró, porrué, porrúek (iz.): 1. joint, marijuana cigarette; 2. leak / 1. porro; 2. puerro.

porrusálda, porrusáldie, porrusáldak (iz.): leak soup / sopa de puerros.

portadá, portadie, portádak edo azál, azalá, azálak (iz.): cover page / portada.

portál, portalá, portálak (iz.): doorway / portal.

portaminas, portaminasa, portaminasak (iz.): propelling pencil / portaminas.

pórtu, pórtue, pórtuek (iz.): port, harbor / puerto.

portzelána, portzelánie, portzelának (iz.): china / porcelana.

posadéro, posadérue, posadéruek (iz.): innman / posadero.

póse, pósie, pósiek (iz.): composture / pose.

posesíba, posesíbie, posesíbak (izond.): possessive (female) / posesiva.

posesíbo, posesíbue, posesíbuek (izond.): possessive (male) / posesivo.

postál, postalá, postálak (iz.): postal card / carta postal.

póste, póstie, póstiek (iz.): post / poste.

póster, pósterra, pósterrak (iz.): poster / poster.

posturá, posturie, postúrak (iz.): position / postura, posición.

póte, pótie, pótiek (iz.): 1. drink, esp. of wine; 2. can / 1. pote, trago; 2. bote (de conservas, etc.).

poténte, poténtie, poténtiek (izond.): powerful / potente.

poténtzi, poténtziye, poténtziyek (iz.): power / potencia.

potéo, potéue, potéuek (iz.): wine drinking / poteo.

potoldú da, potóltzea (ad.): to become fat / engordar.

potólera, potólerie, potólerak (iz.): fatness / grosor, gordura.

pótro, pótrue, pótruek (iz.): testicle / testículo.

potzú, potzué, potzúek (iz.): well / pozo.

poxpolin, poxpoliñe, poxpoliñek (iz.): pretty / niña bonita.

póxpolo, póxpolue, póxpoluek (iz.): match / cerilla.

poz, pozá, pózak (iz.): happiness / alegría.

pozík (adb.): happy / feliz, contento/a.

poztú da, póztea (ad.): to become happy / alegrarse.

prejiu $d u$, prejitzeu (ad.): to fry / freir.

prémi, prémiye, prémiyek (iz.): need / necesidad.

prémiyo, prémiyue, prémiyuek (iz.): prize / premio.

prentzá, prentzié, préntzak (iz.): press (media) / prensa (comunicación de masas).

preokupáziyo, preokupáziyue, preokupáziyuek (iz.): worry / preocupación.

preparátibo, preparátibue, preparátibuek (iz.): preparation / preparativo.

preparáu dulda, preparátzeu/preparátzea (ad.): to prepare, to get ready / preparar(se),

acicalarse.

présa, présie, présak (izond.): female prisoner / presa, rea.

presá, presié, présak (iz.): 1. damn; 2. hurry / 1. presa (de río); 2. prisa.

presidénte, presidéntie, presidéntiek (iz.): president / presidente.

presidéntzi, presidéntziye, presidéntziyek (iz.): presidency / presidencia.

presidiu $d u$, presiditzeu (ad.): to preside / presidir.

presionáu $d u$, presionátzeu (ad.): to pressure / presionar.

presiyó, presiyúe, presíyuek (iz.): pressure / presión. 
préso, présue, présuek (izond.): male prisoner / preso, reo. préziyo, préziyue, préziyuek (iz.): cost, price / coste, importe. pribáu, pribaué, pribáuek (izond.): private / privado. printzésa, printzésie, printzésak (iz.): princess / princesa. printzipe, printzipie, printzipiek (iz.): prince / príncipe. priorídade, priorídadie, priorídadiek (iz.): priority / prioridad. probadóre, probadórie, probadóriek (iz.): dressing room / probador de ropa. probetxú, probetxúe, probétxuek (iz.): profit / provecho.

probáu du, probátzeu (ad.) : 1. to try, to taste; 2. to try, to attempt / 1. probar, degustar; 2. probar, intentar.

probintzi, probintziye, probintziyek (iz.): province / provincia. probléma, problémie, problémak (iz.): problem / problema.

problemátiko, problemátikue, problemátikuek (izond.): problematic / problemático/a, complejo/a.

proféta, profétie, profétak (iz.): prophet / profeta.

profezi, profeziye, profezíyek (iz.): prophecy / profecía.

proibiu du, proibitzeu (ad.): to prohibit, to hinder / prohibir, impedir. proklamáu da, proklamátzea (ad.): to proclaim / proclamarse. promésa, promésie, promésak (iz.): promise / promesa. prometiu du, prometitzeu (ad.): to promise / prometer. propagánda, propagándie, propagándak (iz.): propaganda / propaganda. propiedáde, propiedádie, propiedádiek (iz.): property / propiedad, terreno. propiétayo, propiétayue, propiétayuek (iz.): owner / propietario. próstata, próstatak (iz.): prostate / próstata. proteina, proteinie, proteinak (iz.): protein / proteína. protésta, protéstie, protéstak (iz.): protest / complaint protesta, queja. protestáu $d u$, protestátzeu (ad.): to protest / protestar. pruéba, pruébie, pruébak (iz.): try, attempt / prueba, intento. publikáu du, publikátzeu (ad.): to publish / publicar. publikáziyo, publikáziyue, publikáziyuek (iz.): publication / publicación. públiko, públikue, públikuek (iz., izond.): public / público/a. publizídade, publizídadie, publizídadiek (iz.): publicity / publicidad. puésto, puéstue, puéstuek (iz.): position, place / puesto. pulmói, pulmoyé, pulmóyek (iz.): lung / pulmón. pulmoní, pulmoníye, pulmoníyek (iz.): pneumonia / pulmonía. pultzazíyo, pultzaziyue, pultzazíyuek (iz.): pulse, beat / pulsación. pultzéra, pultzérie, pultzérak (iz.): bracelet / pulsera. pultzó, pultzué, pultzúek (iz.): 1. pulse; 2. steady hand / pulso. púnta, púntie, púntak (iz.): point / punta.

puntapáx, puntapáxa, puntapáxak (iz.): nail / clavo. púnto, púntue, púntuek (iz.): point, period / punto. pus, pusé, púsek (iz.): pus / pus. pútz (e)in du, pútz (e)itéu (ad.): to blow / soplar. puzkáu du, puzkátzeu (ad.): to break / romper. puzkér, puzkerrá, puzkérrak (iz.): fart / pedo. puztú du, púzteu (ad.): to inflate / hinchar, inflar(se). 


\section{$\mathbf{R}$}

rebeláu dulda, rebelátzeu, rebelátzea (ad.): to reveil / rebelar(se).

rebisáu du, rebisátzeu (ad.): to revise / revisar.

rebisiyo, rebisiyue, rebisíyuek (iz.): revision / revisión.

rebista, rebistie, rebistak (iz.): magazine, journal / revista.

rekortáu du, rekortátzeu (ad.): to cut out / recortar.

rekórte, rekórtie, rekórtiek (iz.): cut out / recorte.

resultáu, resultáne, resultánek (iz.): result / resultado.

retiráu dulda, retirátzeu, retirátzea ${ }^{17}$ (ad.): to retire / retirar(se).

retratáu du, retratátzeu (ad.): to portrait / retratar.

rezéta, rezétie, rezétak ${ }^{18}$ (iz.): recipe; prescription / receta.

rezetáu du, rezetátzeu (ad.): to prescribe / recetar.

radár, radarrá, radárrak (iz.): radar / radar.

rádiyo, rádiyue, rádiyuek (iz.): radio / radio.

rára, rárie, rárak (izond.): rare, strange (female) / rara, extraña.

ráro, rárue, ráruek (izond.): rare, strange (male) / raro, extraño.

raziyó, raziyúe, razíyuek (iz.): ration / ración.

régla, réglie, réglak (iz.): ruler / regla.

reglaméntu, reglaméntue, reglaméntuek (iz.): reglament / reglamento.

reuniú da, reunitzea (ad.): to get together, to gather / juntarse.

ritmo, ritmue, ritmuek (iz.): rhythm / ritmo.

ríxo, ríxue, ríxuek (iz.): curl / rizo.

robót, robotá, robótak (iz.): robot / robot.

róllo, róllue, rólluek (iz.): 1. roll 2. boring thing / rollo.

rotuládore, rotuládorie, rotuládorak (iz.): marker / rotulador.

róxa, róxa, róxak (izond.): pink / rosa, rosado/a, rosáceo/a.

rúlo, rúlue, rúluek (iz.): hair-curler / rulo.

\section{S}

sagár, sagarrá, sagárrak (iz.): apple / manzana.

sagárdo, sagárdue, sagárduek (iz.): cider / sidra.

sagráu, sagraué, sagráuek (izond.): sacred / sagrado/a.

sáke, sákie, sákiek (iz.): 1. serve (sports); 2. good apetite / 1. saque, servicio (deportes);

2. gran apetito.

sakón, sakoná, sakónak (izond.): deep / profundo.

sakondú $d u$, sakóntzeu (ad.): to deepen / profundizar.

sakónera, sakónerie, sakónerak (iz.): depth / profundidad.

17 Bokal epentetikodun formak ere erabitzen dira, azentuan aldaketak gertatuz: erretírau daldu, erretíratzeal erretíratzeu.

18 Aurreko belaunaldietan bokal epentetikodun formak ere erabitzen dira, hots, errezéta, errezétie, errezétak. 
sakrifiziyo, sakrifiziyue, sakrifiziyue (iz.): sacrifice / sacrificio.

sakriléjiyo, sakriléjiyue, sakriléjiyuek (iz.): sacrilege / sacrilegio.

sakristáu, sakristáue, sakrístauek (iz.): sacristan / sacristán.

sakú, sakué, sakúek (iz.): bag / saco.

sála, sálie, sálak (iz.): livingroom / sala (de estar).

salbáu du, salbátzeu (ad.): to save / salvar.

salbaziyo, salbazíyue, salbazíyuek (iz.): salvation; rescue / salvación.

saldá, saldié, sáldak (iz.): soup, broth / caldo de sopa.

saldú du, sáltzeu (ad.): to sell / vender.

saleró, salérue, saléruek (iz.): wit, charm / salero, gracia.

salitre, salitrie, salitriek (iz.): sea water / agua marina.

salói, salóye, salóyek (iz.): hall / salón.

saltáu du, saltátzeu (ad.): to jump / saltar.

sálto (e)in du, sálto (e)itéu (ad.): to jump / saltar.

sálto, sáltue, sáltuek (iz.): jump / salto.

saltzá, saltzié, sáltzak (iz.): sauce / salsa.

sáltzen (adb.): on sale / en venta.

saltzerá, saltzerie, saltzérak ${ }^{19}$ (izond.): busybody (female) / salsera, enredadora.

saltzeró, saltzerúe, saltzéruek (izond.): busybody (male) / salsero, enredador.

saludáu du, saludátzeu (ad.): to greet / saludar.

salúdo, salúdue, salúduek (iz.): greetings / saludo.

samíñ samiñé, samiñek (iz.): grief / dolor muy amargo.

sanátoyo, sanátoyue, sanátoyuek (iz.): sanarorium, nursing home / sanatorio.

sáno, sánue, sánuek (izond.): healthy, sane, good-hearted / sano/a, cuerdo/a, de buen corazón.

saré, sarié, saríek (iz.): net / red.

sarjénto, sarjéntue, sarjéntuek (iz.): sergeant / sargento.

sarjentóna, sarjentónie, sarjentónak (izond.): bossy woman / sargentona, mujer dominante.

sarrí (adb.): often / a menudo.

sartú du/da, sártzeu/sártzea (ad.): to get in, enter / entrar, meter.

sartu-érten, sartu-értena, sartu-értenak (iz.): massive flow of people, in and out / afluencia masiva.

sasí, sasiyé, sasiyek (iz.): bush / zarzal, arbusto.

sasiárte, sasiártie, sasiártiek (iz.): bush / zarzal.

sasói, sasoyé, sasóyek (iz.): time, season / época, tiempo.

satisfáziyo, satisfáziyue, satisfáziyue (iz.): satisfaction / satisfacción.

satisfétxa, satisfétxie, satisfétxak (izond.): satisfied, happy (female) / satisfecha, feliz.

satisfétxo, satisfétxue, satisfétxuek (izond.): satisfied, happy (male) / satisfecho, feliz.

19 Hitz honen forma femenino zein maskulinoek baimentzen dituzte saltzéro/saltzéra, saltzérue/saltzérie, formak ere. Halere, aurreko kasuetan bezala, gaztelaniarako hitzaren kalko nabarmenagoa izatea leporatzen zaie, eta azentua silaba bat aurrerago izatea hobesten da. 
satór, satorrá, satórrak (iz.): mole / topo.

sáuna, sáunie, sáunak (iz.): sauna / sauna.

sebillána, sebillánie, sebillának (izond.): Sevillian (female) / sevillana.

sebilláno, sebillánue, sebillánuek (izond.): Sevillian (male) / sevillano.

séda, sédie, sédak (iz.): silk / seda.

segí du, segitzeu (ad.): 1. to follow 2. to keep on / seguir.

segurídade, segurídadie, segurídadiek edo segurtásun, segurtásune, segurtásunek (iz.): security, safety / seguridad.

segúro, segúrue, segúruek (iz.): insurance / seguro.

segurú (adb.): surely / seguramente.

segurú, segurúe, segurúek (izond.): safe / seguro.

ségurunez (adb.): surely, probably / seguramente, probablemente.

seitúen (adb.): right away / en seguida.

sekadóre, sekadórie, sekadórak (iz.): hair drier / secador (de pelo).

sekáu du, sekátzeu edo leortú du, leórtzeu (ad.): to dry / secar.

sekréto, sekrétue, sekrétuek (iz., izond.): secret / secreto.

sékula (adb.): never; ever / nunca, jamás; alguna vez.

sékula ez (adb.): never / nunca, jamás.

sékulako, sékulakue, sékulakuek ${ }^{20}$ (izond.): extrordinary / enorme, extraordinario/a.

selláu du, sellátzeu (ad.): to seal / sellar.

sem(e)álaba, sem(e)álabak (iz.): children / hijos (de ambos sexos).

semé, semié, semiek (iz.): son / hijo.

seminarísta, seminarístie, semináristak (iz.): seminarist / seminarista.

seminayo, seminayue, seminayuek (iz.): seminary / seminario (de curas).

senadóre, senadórie, senadóriek (iz.): senator / senador.

senáu, senáue, senáuek (iz.): senate / senado.

sendáu dulda, sendátzeu/sendátzea (ad.): to heal (oneself) / curar(se), sanar(se).

sendó, sendué, sendúek (izond.): strong / firme, fuerte.

sentidó, sentidúe, sentidúek (iz.): sense, meaning / sentido, significado.

sentiméntal, sentiméntala, sentiméntalak (izond.): sentimental / sentimental.

sentiméntu, sentiméntue, sentiméntuek (iz.): feeling / sentimiento.

sentiú du, sentitzeu (ad.): to feel / sentir.

sentzazíyo, sentzazíyue, sentzazíyuek (iz.): sensation / sensación.

señaláu $d u$, señalátzeu (ad.): to point out / señalar.

señalé, señalie, señáliek (iz.): sign (esp. traffic sign) / señal (esp. de tráfico).

separáu dulda, separátzeu/separátzea (ad.): to separate / separar(se).

separáziyo, separáziyue, separáziyuek (iz.): separation / separación.

serbilléta, serbillétie, serbillétak (iz.): napkin / servilleta.

serbiu $d u$, serbitzeu (ad.): to serve / servir.

serenáta, serenátie, serenátak (iz.): serenade / serenata. 
seriedáde, seriedádie, seriedádiek (iz.): seriousness / seriedad. sériyo (adb.): seriously / de veras, en serio. sériyo, sériyue, sériyuek (izond.): serious (male) / serio. sermói, sermoyé, sermóyek (iz.): sermon / sermón. sesiyó, sesiyúe, sesiyuek (iz.): session / sesión. silla, sillie, síllak edo aulkí, aulkiyé, aulkíyek (iz.): chair / silla. sillói, silloyé, sillóyek (iz.): armchair / sillón. sindikáto, sindikátue, sindikátuek (iz.): trade union / sindicato. sintétiko, sintétikue, sintétikuek (izond.): synthetic / sintético. siñismén, siñisména, siñisménak (iz.): faith, belief / creencia, fe. siñistú $d u$, siñisteu (ad.): to believe / creer.

siréna, sirénie, sirénak (iz.): 1. siren; 2. mermaid / 1. sirena (ruido); 2. sirena (ser mitológico).

sóbra, sóbrie, sóbrak (iz.): leftovers / restos, sobras. sóbran (adb.): as leftovers / de sobra. sobráu da, sobrátzea (ad.): to be more than enough / sobrar. sóbre, sóbrie, sóbriek (iz.): envelop / sobre. sobrebibiu du, sobrebibitzeu (ad.): to survive / sobrevivir. sofakáma, sofakámie, sofakámak (iz.): couch-bed / sofá cama. sofistíkada, sofistikadie, sofistikadak (izond.): sofisticated (female) / sofisticada. sofistíkau, sofistíkaue, sofistíkauek (izond.): sofisticated (male) / sofisticado. sofistíkaziyo, sofistíkaziyue, sofistíkaziyuek (iz.): sofistication / sofisticación. sofokánte, sofokántie, sofokántiek (izond.): suffocating / sofocante. sofokáu da, sofokátzea (ad.): to sofocate / sofocar(se). soká, sokié, sókak (iz.): rope / cuerda, soga. sokamútur, sokamúturre, sokamúturrek (iz.): running of cows / encierro de vaquillas. sokatíra, sokatírie, sokatírak (iz.): tug-of-war / soka-tira. sokorrísta, sokorrístie, sokorrístak (iz.): life-saver / socorrista. solféo, solféue, solféuek (iz.): solfa / solfeo. solista, solistie, solistak (iz.): soloist / solista (cantante). soltáu du, soltátzeu (ad.): to free / soltar, librar, largar. soltéra, soltérie, soltérak (izond.): single (female) / soltera. soltéro, soltérue, soltéruek (izond.): single (male) / soltero. solturá, solturie, soltúrak (iz.): self-confidence / soltura, desparpajo. sonáu du, sonátzeu (ad.): to sound / sonar. sonbrilla, sonbrillie, sonbrillak (iz.): awning / sombrilla. sondéo, sondéue, sondéuek (iz.): sounding / sondeo. soñile)n edo gañí(e)n (adb.): carrying, wearing / a cuestas, encima. sopráno, sopránue, sopránuek (iz.): soprano / soprano. sorbálda, sorbaldie, sorbáldak (iz.): shoulder / hombro. sorgin, sorgiñé, sorgiñek (iz.): witch / bruja. sortéo, sortéue, sortéuek (iz.): drawing, raffle / sorteo. sortú $d u$, sórtzeu (ad.): to create / crear. sósa, sósie, sósak (izond.): dull (female) / sosa, parada. sóso, sósue, sósuek (izond.): 1. dull (male); 2. without salt / 1. soso, abobado; 2. soso, sin sal. 
sospetxáu du, sospetxátzeu (ad.): to suspect / sospechar. sostén, sostená, sosténak (iz.): brasier / sostén, sujetador. sotána, sotánie, sotának (iz.): cassock, soutane / sotana. sótano, sótanue, sótanuek (iz.): basement / sótano.

su, súe, súek (iz.): fire / fuego.

subúrbiyo, subúrbiyue, subúrbiyuek (iz.): suburb / suburbio.

sudúr, sudurré, sudúrrek (iz.): nose / nariz.

suéldo, suéldue, suélduek (iz.): salary / sueldo.

sufrimiénto, sufrimiéntue, sufrimiéntuek (iz.): suffering / sufrimiento.

sufriú $d u$, sufritzeu (ad.): to suffer / sufrir.

sugé, sugié, sugíek (iz.): snake / serpiente, culebra.

sujerénte, sujeréntie, sujeréntiek (izond.): suggestive / sugerente.

sujeréntzi, sujeréntziye, sujeréntziye (iz.): suggestion / sugerencia.

sujeriu du, sujeritzeu (ad.): to suggest / sugerir.

sukálde, sukáldie, sukáldiek (iz.): kitchen / cocina.

susmáu du, susmátzeu edo sospetxáu du, sospetxátzeu (ad.): to suspect / sospechar.

susmó, susmué, susmúek (iz.): suspicion / sospecha.

suspendiu du, suspenditzeu (ad.): to suspend; to fail / suspender.

suspéntzo, suspéntzue, suspéntzuek edo káte, kátie, kátiek (iz.): failing grade / suspenso. sustántzi, sustántziye, sustántziyek (iz.): 1 . substance; 2 . depth of character / sustancia. sústo, sústue, sústuek (iz.): scare / susto.

sustrái, sustráye, sustráyek (iz.): root / raíz.

sutondó, sutondúe, sutónduek (iz.): fireplace, near the fire place / lugar junto al fuego.

$\mathrm{T}$

ta (junt.): 1. and; 2. because (after the verb) / 1. y; 2. porque, dado que (despues del verbo).

tabáko, tabákue, tabákuek (iz.): tobacco / tabaco.

taberná, tabernie, tabérnak (iz.): bar, tavern / bar, taberna.

takílla, takíllie, takíllak (iz.): 1. ticket window; 2. locker / 1. taquilla (de venta, cine); 2.

taquilla (escolar).

takilléro, takillérue (iz.): ticket seller / taquillero.

takói, takoyé, takóyek (iz.): heel / tacón.

tálla, tállie, tállak (iz.): size / talla.

tallér, tallerrá, tallérrak (iz.): workshop / taller.

tálo, tálue, táluek (iz.): corncake / talo, torta de maíz.

tamáño, tamáñue, tamáñuek (iz.): size / tamaño.

tambór, tamborrá, tambórrak (iz.): drum / tambor.

tamborréro, tamborrérue, tamborréruek (iz.): drum player / tamborilero.

tánda, tándie, tándak (iz.): batch, group / tanda, grupo.

tángo, tángue, tánguek (iz.): tango / tango.

tánke, tánkie, tánkiek (iz.): tank, armored vehicle / tanque, carro de combate.

tánta, tántie, tántak (iz.): drop / gota.

tánto, tántue, tántuek (iz.): point, goal / tanto, punta, gol.

tapá, tapié, tápak (iz.): lid / tapa. 
tapáu du, tapátzeu (ad.): to cover / tapar, cubrir.

tapói, tapoyé, tapóyek (iz.): plug / tapón.

tardáu du, tardátzeu (ad.): to take time / tardar.

tarjéta, tarjétie, tarjétak (iz.): card / tarjeta.

tarrina, tarrinie, tarrinak (iz.): cup (e.g. of ice-cream) / tarrina.

tárro, tárrue, tárruek (iz.): pot / maceta, tiesto.

tárta, tártie, tártak (iz.): cake / tarta.

tárte, tártie, tártak (iz.): interlude, break; space in between / intermedio, tiempo libre;

espacio entre dos cosas.

tatxáu du, tatxátzeu (ad.): to cross out / tachar.

tatxói, tatxoyé, tatxóyek (iz.): crossing our, stain / tachón.

té, tié, tiek (iz.): tea / té.

téla, télie, télak (iz.): cloth / tela.

telebisiyo, telebisiyue, telebisiyuek (iz.): television / televisión.

telefonista, telefonistie, telefónistak (iz.): telephone operator / telefonista.

teléfono, teléfonue, teléfonuek (iz.): telephone / teléfono.

telegráma, telegrámie, telegrámak (iz.): telegram / telegrama.

tellatú, tellatúe, tellátuek (iz.): roof / tejado.

telói, teloyé, telóyek (iz.): curtain / telón.

téma, témie, témak (iz.): topic / tema.

tendói, tendoyé, tendóyek (iz.): tendon, sinew / tendón.

tenedóre, tenedórie, tenedórak (iz.): fork / tenedor.

teniénte, teniéntie, teniéntiek (iz.): lieutenant / teniente.

ténis, ténise (iz.): tennis / tenis.

tenór, tenorrá, tenórrak (iz.): tenor / tenor.

ténpera, ténperie, ténperak (iz.): tempera / témpera.

tenperátura, tenperáturie, tenperáturak (iz.): temperature / temperatura.

tenporáda, tenporádie, tenporádak (iz.) : period, season / temporada.

tenporál, tenporála, tenporálak (iz.): tempest / temporal, tempestad.

tentadóre, tentadórie, tentadóriek (izond.): tempter / tentador, burlador.

tentáu du, tentátzeu (ad.): to tempt / tentar.

tentaziyo, tentazíyue, tentazíyuek (iz.): temptation / tentación.

ténte (adb.): standing / de pie.

tentziyó, tentziyúe, tentzíyuek (iz.): tension / tensión.

tentzó, tentzué, tentzúek ${ }^{21}$ (izond.): tense / tenso.

térmo, térmue, térmuek (iz.): thermos / termo.

terráza, terrázie, terrázak (iz.): terrace / terraza.

terréno, terrénue, terrénuek (iz.): terrain / terreno.

tertúli, tertúliye, tertúliyek (iz.): social gathering / tertulia.

test, testá, téstak (iz.): test / test.

21 Hitz honek baimentzen ditu téntzue, téntzuek formak ere. Halere, gaztelaniarako kutsu nabarmenagoa izatea azpimarratu zuten hiztegia berrikusi zuten Azpeitiarrek. 
tési, tésiye, tésiyek (iz.): thesis / tesis.

tesina, tesinie, tesinak (iz.): undergraduate thesis / tesina.

tesoréro, tesorérue, tesoréruek (iz.): treasurer / tesorero/a.

testaménto, testaméntue, testaméntuek (iz.): testament, will / testamento.

testigo, testígue, testíguek (iz.): witness / testigo.

tía, tía, tíak (iz.): aunt / tía.

tíla, tílie, tílak (iz.): lime tea / tila.

timadóre, timadórie, timadóriek (iz.): swindler, trickster / timador, embaucador.

timbre, tímbrie, tímbriek (iz.): bell / timbre.

timáu du, timátzeu (ad.): to swindle / timar.

tímo, tímue, tímuek (iz.): rip off / timo, engaño.

tinta, tintie, tintak (iz.): ink / tinta.

tintáu du, tintátzeu (ad.): to dye / teñir.

tintoréi, tintoréye, tintoréyek (iz.): dry cleaner's / tintorería.

tipa, típie, típak (iz.): woman (despective) / mujer, tía (despectivo).

típo, tipue, tipuek (iz.): 1. guy; 2. body shape / 1. individuo, tipo; 2. tipo, figura.

tipúla, tipúlie, tipúlak (iz.): onion / cebolla.

tiradóre, tiradórie, tiradóriek (iz.): drawer / cajón.

tiránte, tirántie, tirántiek (iz.): suspenders / tirante(s).

tíro, tírue, tíruek (iz.): shot / tiro, disparo.

tirokáu du, tirokátzeu (ad.): to shoot repeteadly / tirotear.

tirotéo, tirotéue, tirotéuek (iz.): shootout / tiroteo.

ti-ta (adb., iz., onomat.): quickly, in a jiffy / rápidamente, en un abrir y cerrar de ojos.

E.g.: etxé au ti-ta batén garbiú ber da, e? 'this house has to be cleaned in a jiffy' / 'hay

que limpiar esta casa en un periquete, ¿eh?'.

tití, titiyé, titíyek (iz.): breast / pecho, teta.

toálla, toállie, toállak (iz.): towel / toalla.

tobogán, tobogána, tobogának (iz.): slide / tobogán.

tokí, tókiye, tókiyek (iz.): place /lugar, sitio.

toldó, toldué, toldúek (iz.): awning / toldo.

toleránte, tolerántie, tolerántiek (izond.): tolerant / tolerante, permisivo.

toleráu $d u$, tolerátzeu (ad.): to tolerate / tolerar.

tolestú $d u$, tolésteu (ad.): to fold / doblar (las sábanas o ropa, mayormente).

tomáte, tomátie, tomátiek (iz.): tomato / tomate.

tómo, tómue, tómuek (iz.): volume (book) / tomo.

tóno, tónue, tónuek (iz.): tone / tono.

tónta, tóntie, tóntak (izond.): stupid (female) / tonta, estúpida.

tontakéi, tontakéye, tontakéyek (iz.): silliness / tontada, bobada.

tónto, tóntue, tóntuek (izond.): stupid (male) / tonto, alelado.

tontór, tontorrá, tontórrak (iz.): summit / cima, cumbre.

tóntotu da, tontótzea (ad.): to become stupid / volverse tonto.

topáu du, topátzeu (ad.): to find, to meet / encontrar.

tópo (e)in du, tópo (e)itéu (ad.): to run into / topar, encontrarse frente a frente.

torbellino, torbellinue, torbellinuek (iz.): whirlwind / torbellino.

toreáu du, toreátzeu (ad.): 1. to fight a bull; 2. to tease / 1. torear; 2. tomar el pelo, torear. 
toreró, torerúe, toréruek ${ }^{22}$ (iz.): bullfighter / torero.

tórpe, tórpie, tórpiek edo trakétz, traketzá, trakétzak (izond.): clumsy / torpe.

torré, torrié, torriek (iz.): tower / torre.

tortílla, tortíllie, tortíllak (iz.): omelette / tortilla.

tostáda, tostádie, tostádak (iz.): toast / tostada.

tostáu du, tostátzeu (ad.): to toast / tostar.

totál, totalá, totálak (iz.): total / suma total.

trabá, trabié, trábak (iz.): hindrance, obstacle / estorbo, traba.

tradiziónal, tradiziónala, tradiziónalak (izond.): traditional / tradicional.

tradizíyo, tradizíyue, tradizíyuek (iz.): tradition / tradición.

tráfiko, tráfikue, tráfikuek (iz.): traffic / tráfico.

tragáu du, tragátzeu (ad.): to swallow / tragar(se).

trágo, trágue, tráguek (iz.): 1. gulp, drink; 2. alcoholic drink / trago.

trámo, trámue, trámuek (iz.): section / tramo.

trankill (adb.): quietly / tranquilamente.

trankíll, trankillé, trankillek edo lasái, lasayé, lasáyek (izond.): quiet, tranquil, calm I tranquilo/a.

tranpá, tranpié, tránpak (iz.): trap / trampa.

tranpoliñ tranpolíne, tranpoliñek (iz.): springboard / trampolín.

tranpósa, tranposíe, tranpósak (izond.): swindler (female) / tramposa.

tranpóso, tranposúe, tranpósuek (izond.): swindler (male) / tramposo.

trapú, trapué, trapúek (iz.): rag / trapo.

trasparénte, trasparéntie, trasparéntiek (izond.): transparent / transparente.

trasparéntzi, trasparéntziye, trasparéntziyek (iz.): transparence / transparencia.

traspasáu du, traspasátzeu (ad.): to penetrate / traspasar.

trasplantáu du, trasplantátzeu (ad.): to transplant / transplantar.

trasplánte, trasplántie, trasplántiek (iz.): transplant / transplante.

traspórte, traspórtie, traspórtiek (iz.): transportation / transporte.

trasportísta, trasportístie, trasportístak (iz.): carrier / transportista.

trastadá, trastadie, trastádak edo biurríkei, biurríkeye, biurríkeyek (iz.): mischief I trastada, travesura.

trásto, trástue, trástuek (iz.): 1. tool; 2. mischievous child / 1. trasto, cacharro, cualquier utensilio; 2 . niño travieso y revoltoso, trasto.

tratánte, tratántie, tratántiek (iz.): cattle dealer / tratante, vendedor de ganado.

tratáu du, tratátzeu (ad.): to treat / tratar.

tratáu, trataué, tratáuek (iz.): treaty / tratado, acuerdo.

tratú, tratué, tratúek (iz.): treatment / trato.

trazáu du, trazátzeu (ad.): to trace / trazar.

tren, trená, trénak (iz.): train / tren.

trentzá, trentzié, tréntzak (iz.): plait / trenza.

trikití, trikitíye, trikitíyek (iz.): type of accordion / tipo de acordeón, trikitixa.

tripá, tripié, trípak (iz.): 1. tripe, intestines; 2. belly / tripa.

22 Hitz honek baimentzen ditu toréro, torérue formak ere, gaztelaniarako kutsua izanik ordea. 
tripáki, tripákiye, tripákiyek (iz.): tripe / callo(s).

tripakó miñ, tripakó miñé, tripakó miñek (iz.): bellyache / dolor de tripa.

tristé, tristié, tristiek edo trixté, trixtié, trixtíek (izond.): sad / triste.

tristetú da, tristétzea (ad.): to become sad, to sadden / entristecerse.

tronpéta, tronpétie, tronpétak (iz.): trumpet / trompeta.

trontzá, trontzié, tróntzak (iz.): slide / rodaja.

trópa, trópie, trópak (iz.): troop / tropa.

tropelien (adb.): all rushing together / en tropel.

trúko, trúkue, trúkuek (iz.): trick / truco.

trumói, trumoyé, trumóyek (iz.): thunder / trueno.

ttípi-ttápa (adb.): step by step / pasito a pasito.

tuberí, tuberíye, tuberiyek (iz.): pipe / tubería.

túbo, túbue, túbuek (iz.): tube / tubo.

túfo, túfue, túfuek edo kiétz, kietzá, kiétzak (iz.): stench / tufo, hedor.

tunél, tunelá, tunélak (iz.): tunnel / túnel.

tupé, tupié, tupiek (iz.): toupee / tupe.

turísmo, turísmue, turismuek (iz.): tourism / turismo.

turísta, turistie, turístak (iz.): tourist / turista.

turistiko, turístikue, turistikuek (izond.): touristic / turístico.

turrói, turroyé, turróyek (iz.): nougat / turrón.

turúta, turútie, turútak (iz.): small trumpet / turuta, trompeta pequeña.

txábola, txábolie, txábolak (iz.): hut / chabola, choza.

txakéta, txakétie, txakétak (iz.): jacket / chaqueta.

txaketói, txaketóye, txaketóyek (iz.): big jacket / chaquetón.

txakolin, txakoliñe, txakoliñek (iz.): a local young white wine / chacolí.

txakúr, txakurré, txakúrrek (iz.): dog / perro/a.

txál, txalá, txálak (iz.): 1 . calf ; 2 . vomit/ 1. ternera; 2. vómito.

txalá (e)in du, txalá (e)itéu (ad.): to vomit / vomitar.

txalapárta, txalapártie, txalapártak (iz.): wooden percussion instrument / instrumento

musical de percusión hecho de madera.

txaléko, txalékue, txalékuek (iz.): vest / chaleco.

txalét, txaletá, txalétak (iz.): chalet / chalet.

txalgurá, txalgurie, txalgúrak (iz.): desire to vomit / ganas de vomitar.

txálo, txálue, txáluek (iz.): 1. applause; 2. blow / 1. aplauso; 2. bofetada.

txalúpa, txalúpie, txalúpak (iz.): type of boat / chalupa, lancha.

txamárra, txamárrie, txamárrak (iz.): thick jacket / chamarra.

txánda, txándie, txándak (iz.): turn / turno, vez.

txándal, txándala, txándalak (iz.): tracksuit, sweatsuit / chándal.

txankléta, txanklétie, txanklétak (iz.): rubber slipper / chancleta.

txáno, txánue, txánuek (iz.): hat, hood / gorro, capucha.

txanpáñ txanpañé, txanpáñek (iz.): champagne / champán.

txanpú, txanpué, txanpúek (iz.): shampoo / champú.

txantáje, txantájie, txantájiek (iz.): blackmail / chantaje.

txantajísta, txantajistie, txantajístak (iz.): blackmailer / chantajista. 
txapá, txapié, txápak (iz.): 1. metal plate; 2. boring conversation (among youngsters) / 1. chapa (de la botella, del coche o de la cocina); 2. conversación aburrida (usado por los jóvenes).

txapél, txapelá, txapélak (iz.): hat / chapela.

txar, txarrá, txárrak (izond.): bad / malo.

txarangá, txarangíe, txarángak ${ }^{23}$ (iz.): music band / charanga, banda de música popular. txartél, txartelá, txartélak (iz.): card / tarjeta.

txekór, txekorrá, txekórrak (iz.): male calf, young bull / novillo macho.

txermén, txermená, txerménak (iz.): pear / pera.

txerrí, txerriyé, txerríyek (iz.): pig / cerdo.

txerrikéi, txerrikéye, txerrikeyek (iz.): dirtiness / porquedad, suciedad.

txerríki, txerríkiye, txerríkiyek (iz.): pork / carne de cerdo.

txerritei, txerriteye, txerriteyek (iz.): pigsty / pocilga.

txertó, txertué, txertúek (iz.): vaccination / vacuna.

txibáta, txibátie, txibátak (izond.): tattletale (female) / chivata.

txibáto, txibátue, txibátuek (izond.): tattletale (male) / chivato (normalmente se usa entre niños).

txikí, txikiyé, txikíyek (izond.): little, small / pequeño/a.

txikitán (adb.): in childhood, as a child / en la infancia.

txikitátik (adb.): from childhood / desde la infancia.

txikitéro, txikitérue, txikitéruek (iz.): s.o. who is in the habit of going from bar to bar drinking small glasses of wine / persona que acostumbra a chiquitear, tomar vinos. txikito, txikitue, txikituek (iz.): small glass of wine / chiquito, vaso de vino.

txikiú daldu, txikitzealtxikitzeu (ad.): 1. to make small; 2. to break in little pieces /

1. empequeñecer, reducir; 2 . destrozar, desmenuzar.

txilbór, txilborrá, txilbórrak (iz.): navel / ombligo.

tximeléta, tximelétie, tximelétak (iz.): butterfly / mariposa.

txingor, txingorra, txingorrak (iz.): hail / granizo.

txingurrí, txingurríye, txingúrriyek (iz.): ant / hormiga.

txino, txinue, txinuek (iz.): Chinese / chino/a.

txintxarrí, txintxarríye, txintxárriye ${ }^{24}$ (iz.): rattle / cascabel.

txintxéta, txintxétie, txintxétak (iz.): thumbtack / chincheta.

txintxilik (adb.): hanging / colgando.

txipirói, txipiróye, txipiróyek (iz.): small squid / chipirón, calamar pequeño.

txiribuélta, txiribuéltie, txiribuéltak (iz.): somersault / voltereta.

txirristáu da, txirristátzea (ad.): to slide / resbalar.

txíspa, txíspie, txíspak (iz.): spark / chispa.

txiste, txistie, txistiek (iz.): joke / chiste.

txistósa, txistosíe, txistósak (izond.): funny (female) / chistosa.

txistóso, txistosúe, txistósuek (izond.): funny (male) / chistoso, gracioso.

txístu, txístue, txístuek (iz.): 1. type of flute; 2. whistle / 1. flauta vasca; 2. silbido.

23 txaránga, txarángie, txarángak formak ere onartzen dira, gaztelania kutsua egotzita, ordea.

24 txintxárri, txintxárriye, txintxárriyek azentudun formak ere onartzen dira. 
txistú, txistué, txistúek (iz.): saliva / saliva.

txistué botadú, txistué botatzéu (ad.): to spit / escupir.

txitá, txitíe, txitak (iz.): chick / polluelo.

txitxárro, txitxárrue, txitxárruek (iz.): type of fish / chicharro (pescado).

txintxói, txintxoyé, txintxóyek (iz.): bump on the head, swelling / chichón.

txix, txixé, txixek (iz.): urine / orina.

txixé (e)in du, txixé (e)itéu (ad.): to urinate / orinar, mear.

txixeñéro, txixeñérue, txixeñéruek (izond.): s.o. who urinates a lot / el que orina frecuentemente.

txofér, txoferrá, txoférrak (iz.): driver; conductor/a.

txoíxo, txoíxue, txoíxuek (iz.): type of sausage / chorizo.

txokolátada, txokolátadie, txokolátadak (iz.): hot chocolate feast / chocolatada.

txokoláte, txokolátie, txokolátiek (iz.): chocolate / chocolate.

txokolátina, txokolátinie, txokolátinak (iz.): chocolate (candy) / chocolatina.

txori, txoriyé, txoriyek (iz.): bird / pájaro.

txorkatilla, txorkatíllie, txorkatíllak (iz.): ankle / tobillo.

txorradá, txorradie, txorrádak (iz.): stupid thing / chorrada, tontería.

txórro, txórrue, txórruek (iz.): jet, squirt, stream / chorro.

txósna, txósnie, txósnak (iz.): temporary construction for selling food and drinks /

chozna, chiringuito temporal donde se sirven bebidas y comida.

txotá, txotié, txótak (iz.): knave (cards) / sota.

txotxóla, txotxólie, txotxólak (izond.): stupid (female) / lela, boba.

txupito, txupitue, txupituek (iz.): alcoholic drink, shot / chupito, vasito de licor.

txukún, txukuné, txukúnek (izond.): clean / limpio, aseado.

txúla, txúlie, txúlak (izond.): overbold, stuck-up (female) / chula, engreída.

txulerí, txuleríye, txuleríyek (iz.): bragging / chulería, fanfarronería.

txuléta, txulétie, txulétak (iz.): steak / chuleta.

txuletói, txuletóye, txuletóyek (iz.): big steak / chuletón.

txúlo, txúlue, txúluek (izond.): stuck-up, overbold, braggart (male) / chulo, fanfarrón.

txuringó, txuringúe, txuringuek (iz.): egg white / clara del huevo.

txupáu du, txupátzeu (ad.): to lick, to suck / chupar, lamer.

txupéte, txupétie, txupétiek (iz.): sucker / chupete.

txurí, txuriyé, txuríyek (izond.): white / blanco/a.

txurrerí, txurreriye, txurreríyek (iz.): fritter stall / churrería.

txurrerá, txurreríe, txurrérak (iz.): fritter seller (female) / churrera.

txurreró, txurrerúe, txurréruek (iz.): fritter seller (male) / churrero.

txúrro, txúrrue, txúrruek (iz.): fritter, churro / churro.

\section{$\mathrm{U}$}

udabérri, udabérriye, udabérriyek (iz.): spring / primavera.

udalétxe, udalétxie, udalétxiek (iz.): City Hall, Town Hall / ayuntamiento.

udará, udarie, udárak (iz.): summer / verano.

udazkén, udazkéna, udázkenak (iz.): autumn / otoño.

uélga, uélgie, uélgak (iz.): strike / huelga.

ukáu du, ukátzeu edo negáu du, negátzeu (ad.): to deny / negar. 
ukóndo, ukóndue, ukónduek (iz.): elbow / codo.

ulertú du, ulértzeu (ad.): to understand / comprender.

últzera, últzerie, últzerak (iz.): ulcer / úlcera.

umé, umié, umiek (iz.): child / niño/a, crío/a.

umedáde, umedádie, umedádiek (iz.): wetness, humidity / humedad.

umekéi, umekéye, umekéyek (iz.): childish action / niñería, infantilada.

umemóko, umemókue, umemókuek (izond.): brat, child (despective) / criajo/a, niño/a, mocoso/a (con matiz despectivo).

umetúda, umétzea (ad.): to become like a child / aniñarse, volver a ser niño/a.

umezále, umezálie, umezáliek (izond.): s.o. who likes children / aficionado a los niños,

que le gustan los niños, que se arregla bien con los niños.

umezúrtz, umezúrtze, umezúrtzek (iz.): orphan / huérfano.

umildáde, umildádie, umildádiek (iz.): humility, humbleness / humildad.

umílde, umíldie, umíldiek (izond.): humble / humilde.

umilláu du, umillátzeu (ad.): to humble, to humiliate / humillar.

umoré, umorie, umóriek (iz.): humor, mood / humor, estado de ánimo.

umoréon, umoréona, umoréonak (iz.): good mood / buen humor.

umorétxar, umorétxarra, umorétxarrak (iz.): bad mood / mal humor.

unibértzal, unibértzala, unibértzalak (izond.): universal / universal.

unidáde, unidádie, unidádiek (iz.): unity / unidad.

unifórme, unifórmie, unifórmiek (iz.): uniform / uniforme.

untxí, untxiyé, untxíyek (iz.): rabbit; conejo.

ur, uré, úrek edo ur, udé, údek (iz.): water; agua.

urdiñ urdiñé, urdiñek (izond.): blue / azul.

ureztáu du, ureztátzeu (ad.): to water / regar.

urré, urrié, urriek (iz.): gold / oro.

úrrengo, úrrengue, úrrenguek (izond.): next / siguiente.

urrí, urriyé, urríyek (iz.): October / octubre.

urrundú da, urrúntzea (ad.): to go away / alejar(se).

urrunien (adb.): far / lejos.

urrutí (adb.): far / lejos.

urté, urtié, urtíek (iz.): year / año.

úrtero (adb.): every year / todos los años.

urtézar, urtézarra, urtézarrak (iz.): New Year's Eve / Nochevieja.

urtú da, úrtzea (ad.): to melt / derretir(se).

usái, usayé, usáyek (iz.): smell /olor.

usaindú du, usáintzeu (ad.): to smell / olfatear, oler, desprender olor.

usó, uxúe, uxúek (iz.): pigeon / paloma.

ustél, ustelá, ustélak (izond.): spoiled, rotten / podrido/a.

usteldú da, ustéltzea (ad.): to get spoiled, to rot / pudrirse.

ustelkéi, ustelkéye, ustelkéye (iz.): rottenness, rotten part / podredumbre.

ustú $d u$, ústeu (ad.): to empty / vaciar.

utz, utzé, útzek (izond.): simple, mere / mero, simple.

utzi du, úzteu (ad.): 1. to leave, to abandon; 2. to allow / 1. dejar, abandoner; 2. dejar, permitir.

utzík (adb.): empty / vacío. 


\section{$\mathrm{X}$}

xagú, xagué, xagúek (iz.): mouse / ratón.

xagúxar, xagúxarra, xagúxarrak (iz.): bat (animal) / murciélago.

xaladá, xaladie, xaládak (izond.): amusing, lively (female) / salada, graciosa.

xaláu, xalaué, xaláuek (izond.): amusing, lively (male) / salado, gracioso.

xéi (zenb.): six / seis.

xeikó urrín ibilí da, xeikó urrín ibíltzea (ad.): to play "sixes” (a card game) / jugar a los seises (juego de naipes).

xeiréun (zenb.): six hundred / seiscientos.

xelébre, xelébrie, xelébriek (izond.): funny, peculiar / gracioso/a, peculiar.

xéxtran (adb.): fighting / peleando.

xiestá, xiestié, xiéstak (iz.): siesta, nap / siesta.

xikira (adb.): at least / por lo menos, si quiera.

xímaur, xímaurre, xímaurrek (iz.): manure, fertilizer / estiércol.

ximél, ximelá, ximélak (izond.): withered / marchita.

ximeldú da, ximéltzea (ad.): to wither / marchitarse.

ximúr, ximurré, ximúrrek (iz.): wrinkle / arruga.

ximurtú da, ximúrtzea (ad.): to wrinkle / arrugar.

xirimíri, xirimíriye, xirimíriyek (iz.): drizzle / llovizna.

xixtrín, xixtriñe, xixtríñek (izond.): 1. skinny; 2. whim / 1. raquítico/a; 2. melindre.

xumé, xumié, xumíek (izond.): humble / humilde, modesto/a.

xur, xurré, xúrrek (izond.): stingy / tacaño/a.

\section{$\mathrm{Z}$}

zabál, zabalá, zabálak (izond.): wide, large / ancho/a, amplio/a.

zabaldú du, zabáltzeu (ad.): to open; to widen / abrir; ensanchar.

zabálera, zabálerie, zabálerak (iz.): width / anchura.

zabalik (pred. adj.): open / abierto/a.

záil, zallé, zállek (izond.): difficult / difícil.

zaintzálle, zaintzállie, zaintzálliek (iz.): guardian / guardián/a, cuidador/a.

záiñ zañé, záñek (iz.): vein / vena.

zaitú du, záitzeu (ad.): to take care / cuidar.

zaldí, zaldiyé, zaldíyek (iz.): horse / caballo.

zaletásun, zaletásune, zaletásunek (iz.): tendency, inclination / afición, gusto, tendencia.

zapál, zapalá, zapálak (izond.): flat, flatened / llano/a, aplastado/a.

zapaldú du, zapáltzeu (ad.): to step on something / pisar.

zaparrái, zaparráye, zaparráyek (iz.): shower (rain) / chaparrón.

zapatá, zapatíe, zapátak (iz.): shoe / zapato.

zapatéi, zapatéye, zapatéyek (iz.): shoe store / zapatería.

zapatéro, zapatérue, zapatéruek (iz.): shoe maker / zapatero.

zapatílla, zapatíllie, zapatíllak (iz.): slipper / zapatilla. 
zapátu, zapátue, zapátuek ${ }^{25}$ (iz.): Saturday / sábado.

zaplastéko, zaplastékue, zaplastékuek (iz.): slap / bofetada.

zapóre, zaporie, zapóriek (iz.): flavor / sabor.

zar, zarrá, zárrak (izond.): old / mayor, viejo/a.

zaratá, zaratíe, zarátak (iz.): noise / ruido.

zartú da, zártzea (ad.): to become old / envejecer.

zartzáro, zartzárue, zartzáruek (iz.): old age / vejez.

zatár, zatarrá, zatárrak (izond.): ugly / feo.

zatí, zatiyé, zatíyek (iz.): piece / trozo, pedazo.

záunka éin du, záunka (é)iteu (ad.): to bark / ladrar.

záunka, záunkie, záunkak (iz.): bark (of dog) / ladrido.

záunkaka (adb.): barking / ladrando.

zazpí (zenb.): seven / siete.

zeozé (izord.): something / algo.

$z e a$ (iz.): 1 . that (used to replace a word that does not come to mind); 2 . exclamative expression / 1. eso (término comodín usado muchas veces cuando uno no acierta o no quiere decir la palabra correspondiente); 2. expresión exclamativa. E.g.: zea esan dit, zuena etortzeko '(s)he said that to me, that I should come to you' / 'me ha dicho eso, que vaya donde vosotros'; bai zea! 'no way' (lit. yes, that!)' / ‘qué va! (lit. ¡sí, eso!) (Hualde et al., 1994).

zeátik edo zéba (gald.): why / por qué.

zéin (gald.): who, ABS / quién, ABS.

zéintzui (gald.): to whom, DAT pl. / a quiénes.

zéintzuk (gald.): which (plural) / cuáles.

zelái, zelayé, zeláyek (iz.): field, lawn, prairie / prado, campo.

zelebráu du, zelebrátzeu (ad.): to celebrate / celebrar. cfr. ospáu.

zelebráziyo, zelebráziyue, zelebráziyuek (iz.): celebration / celebración.

zélo, zéluek (iz.): jealousy / celos.

zelozá, zelozíe, zelózak ${ }^{26}$ (izond.): jealous (female) / celosa.

zelozó, zelozúe, zelózuek (izond.): jealous (male) / celoso.

zemát (gald.): how much, how many / cuánto-s.

zentzudún, zentzudúne, zentzudúnek (izond.): sensible / sensato/a, juicioso/a.

zentzugábe, zentzugábie, zentzugábiek (izond.): senseless / sin sentido, insensato/a.

zeñék (gald.): who, ERG / quién, ERG.

zeñén (gald.): whose, GEN / de quién, GEN. E.g.: zeñén etxié da orí? 'whose house is that?'; ‘de quién es esa casa?'

zeñentzát (gald.): for whom / para quién.

$z e \tilde{n} i$ (gald.): to whom, DAT / a quién, DAT.

zeozé (izord.): something, anything / algo, nada.

25 Hitz honek aldakortasun nabarmena azaltzen du, izan ere, zapátu, zapátue, zapátuek zein zápatu, zápatue, zápatuek formak erabiltzen dira.

26 Hitz honek forma femenino zein maskulinoak baimentzen ditu, hots, zelóso/zelósa, zelósuelzelósie. Halere, aurreko kasuetan bezala, gaztelaniarako hitzaren kalko nabarmenagoa izatea leporatzen zaie, eta azentua silaba bat aurrerago izatea hobesten da. 
zepillo, zepíllue, zepilluek (iz.): brush / cepillo.

zer (gald.): what / qué.

zerbéza, zerbézie, zerbézak (iz.): beer / cerveza.

zerbiziyo, zerbiziyue, zerbiziyuek (iz.): service / servicio, utilidad.

zeregín, zeregíne, zeregínek (iz.): occupation / quehacer, ocupación.

zéro, zérue, zéruek (iz.): zero / cero.

zerrá, zerrié, zérrak (iz.): saw / sierra.

zerradúra, zerradúrie, zerradúrak (iz.): bolt, lock / cerradura.

zerrajéro, zerrajérue, zerrajéruek (iz.): locksmith / cerrajero.

zérrautz, zérrautze, zérrautzek (iz.): sawdust / serrín.

zertakó (gald.): what for / para qué.

zerú, zerué, zerúek (iz.): sky; heaven / cielo.

zezén, zezená, zezénak (iz.): bull / toro.

zezenpláza, zezenplázie, zezenplázak (iz.): bullring / plaza de toros.

zigárro, zigárrue, zigárruek (iz.): cigarette / cigarrillo.

zigortú du, zigórtzeu (ad.): to punish / castigar.

zikindú dulda, zikintzeu/zikintzea (ad.): to dirty, to get dirty / ensuciar(se).

zikinkéi, zikinkéye, zikinkéye (iz.): dirtiness / suciedad.

zikiñ, zikiñé, zikiñek (izond.): dirty / sucio/a.

ziklísmo, ziklísmue, ziklísmuek (iz.): biking / ciclismo.

ziklista, ziklístie, ziklístak (iz.): bicyclist / ciclista.

zíklo, zíklue, zíkluek (iz.): cycle / ciclo.

zillár, zillarrá, zillárrak ${ }^{27}$ (iz.): silver / plata.

zillarrézko, zillarrézkue, zillarrézkuek ${ }^{28}$ (izond.): made of silver / plateado/a.

zine, zinie, ziniek (iz.): cinema, movie theater / cine.

zinta, zintie, zintak (iz.): tape / cinta.

zinturói, zinturóye, zinturóyek (iz.): belt / cinturón.

zintzó, zintzué, zintzúek (izond.): sincere, honest, loyal / sincero/a, honrado/a, fiel.

zintzotásun, zintzotásune, zintzotásunek (iz.): honesty, loyalty / honradez, lealtad.

zipriztîn, zipriztîne, zipriztînek (iz.): sprinkling / salpicadura.

zirko, zirkue, zirkuek (iz.): circus / circo.

zirkuito, zirkuítue, zirkuituek (iz.): circuit / circuito.

zirkunferéntzi, zirkunferéntziye, zirkunferéntziyek (iz.): circumference / circunferencia.

zita, zitie, zitak (iz.): appointment, date / cita.

zóna, zónie, zónak (iz.): zone / zona.

zor, zorrá, zórrak (iz.): debt / deuda.

zorakéi, zorakéye, zorakéyek (iz.): craziness, silliness / locura, insustancialidad.

zoráu da, zorátzea (ad.): to become crazy / volverse loco, enloquecer.

zorionak! (iz.): congratulations!; happy birthday! / ¡felicidades!

zoritxarra, zoritxarra, zoritxarrak (iz.): bad luck / mala suerte, desgracia.

zoritxarrez (adb.): unfortunately / desgraciadamente, por desgracia.

27 Hitz honek bokal alternantzia baimentzen du zillerrá, zillérrak formetan.

28 Adjektiboan ere gertatzen da bokal alternantzia, hots, zillerrézko, zillerrézkue, zillerrézkuek. 
zoró, zorué, zorúek (izond.): crazy / loco/a.

zoroétxe, zoroétxie, zoroétxiek: madhouse / manicomio.

zorrí, zorriyé, zorríyek (iz.): louse / piojo.

zorrótz, zorrotzá, zorrótzak (izond.): sharp / agudo, afilado, puntiagudo.

zorroztú du, zorrózteu (ad.): to sharpen / afilar.

zorté, zortié, zortíek (iz.): luck, fortune / suerte, fortuna.

zortzí (zenb.): eight /ocho.

zortzikó, zortzikúe, zortzikúek (iz.): eighth part / octavo.

zotiñ zotiñé, zotiñek (iz.): hiccups / hipo.

zozó, zozué, zozúek (iz.): thrush, type of black bird / tordo.

$z u$ (izord.): you / tú.

zubi, zubiyé, zubiyek (iz.): bridge / puente.

zúek (izord.): you plural (abs or erg) / vosotros/as (ABS o ERG).

zuláu du, zulátzeu (ad.): to make holes / agujerear.

zuló, zulué, zulúek (iz.): hole / agujero.

zutik (adb.): standing (used mostly in church) / de pie (sobre todo en la iglesia).

zutitú da, zutítzea (ad.): to stand / ponerse de pie.

zuzén, zuzená, zuzénak (izond.): right, straight / recto/a, derecho/a.

zuzéndai, zuzendáye, zuzéndayek (iz.): director / director/a.

zuzendú dulda, zuzéntzeulzuzéntzea (ad.): 1. to correct; 2. to straighten up, to set upright; 3 . to direct / 1. corregir; 2 . enderezar; 3 . dirigir.

zuzenien (adb.): directly / en directo, directamente.

\section{ERREFERENTZIAK}

Altuna, P. (1985). Azpeitiko euskal ebakeraz. Euskera, 31(2), 333-340.

Argoitia, J. A., Azkarate, N. \& Gezuraga, X. (1998). Eibarko euskararen esaerak eta bestelako berezitasun batzuk. Eibar: Eibarko Udala.

Askoren artean. (2014). Elhuyar hiztegia. Durango/Usurbil: Elhuyar Fundazioa.

Azpeitia Eizagirre, A. (2003). Zestoarren erretolika: hitzen, esamoldeen, eta atsotitzen bilduma. Zestoa: Zestoako Udala.

Azpiazu, A. (2009). Gipuzkoako hegoaldeko euskara. Legazpi: Burdinola.

Beristain, A. (2018). Azpeitiko euskararen hiztegi dialektal bat - I. Fontes Linguae Vasconum, 125, 7-54.

De Rijk, R. (1970). Vowel interaction in Bizcayan Basque. Fontes Linguae Vasconum, $5,149-168$.

Del Castillo, V., Romo, J. A. \& Giralt, B. (2001). Azkoittiko euskerie. Azkoitia: Azkoitiko Udala.

Elexpuru, J. M. (2005). Bergara aldeko berbak. Bergara: Bergarako Udala.

Etxebarria, T. (1965). Lexicón del euskera dialectal de Eibar. Euskera, 10-11, 1-657.

Fraile, I. \& Fraile, A. (1996). Oiartzungo hizkera. Oiartzun: Oiartzungo Udala.

Gaminde, I. (2002). Bizkaiko euskararen ezaugarri fonologiko batzuen inguruan. Euskalingua, 1, 4-14.

Gaminde, I. (2003). Zaldibar Berbarik Berba. Zaldibar: Zaldibarko Udala.

Goikoetxea, J. (1967). Loyola inguruan osatutako iztegitxoa. Euskera, 12, 25-60. 
Hualde, J. I. (1991). Basque Phonology. Routledge: New York.

Hualde, J. I. \& Beristain, A. (2017). Azpeitiko azentuaren gauzatze fonetikoaz. Fontes Linguae Vasconum, 123, 65-86.

Hualde, J. I. \& Beristain, A. (2019). Bi alofonia-gertakari Azpeitiko euskaran. In A. Etxebarria, A. Iglesias, H. Lejarreta, \& A. Romero (arg.), Traineru bete lagun: Iñaki Gaminde omenduz (pp. 209-228). Bilbo: Euskal Herriko Unibertsitatea.

Hualde, J. I., Elordieta, G. \& Elordieta, A. (1994). The Basque Dialect of Lekeitio. Donostia: Euskal Herriko Unibertsitatea.

Hualde, J. I. \& Gaminde, I. (1997). Vowel interaction in Basque: A nearly exhaustive catalogue. ASJU, 31(1), 211-245.

Izaguirre, C. (1970). El vocabulario vasco de Oñate-Aránzazu y zonas colindantes. ASJU, 4, 3-248.

Makazaga Eizagirre, J. M. (2010). Elgoibarko ahozko euskara. Bilbo: Euskal Herriko Unibertsitatea eta Euskaltzaindia.

Oñederra, M. L. (2004). Fonetika eta fonologia hitzez hitz. Donostia: Euskal Herriko Unibertsitatea.

Zuazo, K. (2008). Euskalkiak: euskararen dialektoak. Donostia: Elkar.

Zuloaga, E. (2017). Beheko bokalaren asimilazioaren historiarako: mendebaleko lekukotasunak. Fontes Linguae Vasconum, 123, 167-199. 